Check for updates

Cite this: RSC Adv., 2018, 8, 23881

\title{
Synthesis of different glutathione-sulfur mustard adducts of verified and potential biomarkers $\dagger$
}

Andreas Bielmann, (D) ab Nicolas Sambiagio, (D) ac Nathalie Wehr, ${ }^{\text {ab }}$ Sandrine GerberLemaire, (DD C Christian G. Bochet (iD) ${ }^{\mathrm{b}}$ and Christophe Curty (DD *a

Sulfur Mustard (SM) is a blistering agent used as a chemical weapon. Glutathione (GSH) is involved in the $\beta$ lyase degradation pathway of SM and recently, bioadducts between SM and GSH were observed in vitro. While these bioadducts have never been isolated from in vivo tests or real poisoning with SM, they could be of interest as potential future biomarkers for the retrospective validation of exposure. We herein report the synthesis of different observed and new potential GSH-SM bioadducts as reference materials for analytical investigation. Two distinct approaches were investigated: a building-block pathway and the direct reaction with GSH. The availability of these references will aid future studies and may lead to the discovery of new GSH-SM biomarkers.

Received 19th April 2018

Accepted 15th June 2018

DOI: $10.1039 / c 8 r a 03360 a$

rsc.li/rsc-advances redness and $0.5 \mathrm{mg} \mathrm{cm} \mathrm{cm}^{-2}$ leads to the formation of huge vesicles. $^{4}$

The reactive alkylating species is generated by intramolecular cyclisation of SM and the formation of an episulfonium ion (Scheme 1). It alkylates cellular DNA and can cross-link DNA strands (intrastrand and interstrand), which inhibits DNA replication and leads to cell death. This is also believed to be the source of the latency period, which corresponds to the time the cell needs for a division. Alkylation of DNA through SM is believed to have long term adverse effects like cancers, chronic respiratory diseases and neurological disorders. ${ }^{4 a, 5}$

SM does not only form adducts with DNA, but also with other biomolecules like proteins or phospholipids. These adducts can be used as biomarkers to retrospectively give evidence for exposure. ${ }^{7}$ Bioadducts of DNA are the most studied. They either contain a 2-(2-(hydroxy)ethylthio)ethyl (HETE) moiety after alkylation and hydrolysis or are cross-linked with a 2-(ethylthio) ethyl (ETE) linker. Experiments with DNA incubated with ${ }^{35} \mathrm{~S}$ labelled SM showed that DNA adducts are mainly formed with guanine $(60 \%)$ and adenine $(8 \%)$. Also, cross-linked guanine was observed (16\%). These adducts have been synthesized to develop analytical methods and were analyzed by LC-MS/MS. ${ }^{8}$ Recently, an adduct between guanine, SM and glutathione (GSH) was discovered in mice exposed to SM, which could be observed by HPLC-MS/MS up to two weeks after exposure. ${ }^{9}$ Bioadducts are also formed with proteins like hemoglobin, albumin, globin and keratin, which can be detected after isolation and digestion with proteases. Adduct formation happens on the nucleophilic sites of the proteins. Alkylation of Val, His, Asp, Cys and Glu has been observed. ${ }^{\mathbf{1 0}}$

GSH is a tripeptide with the formula $\gamma$-Glu-Cys-Gly. It plays a major role as a redox buffer in cells and is involved in 


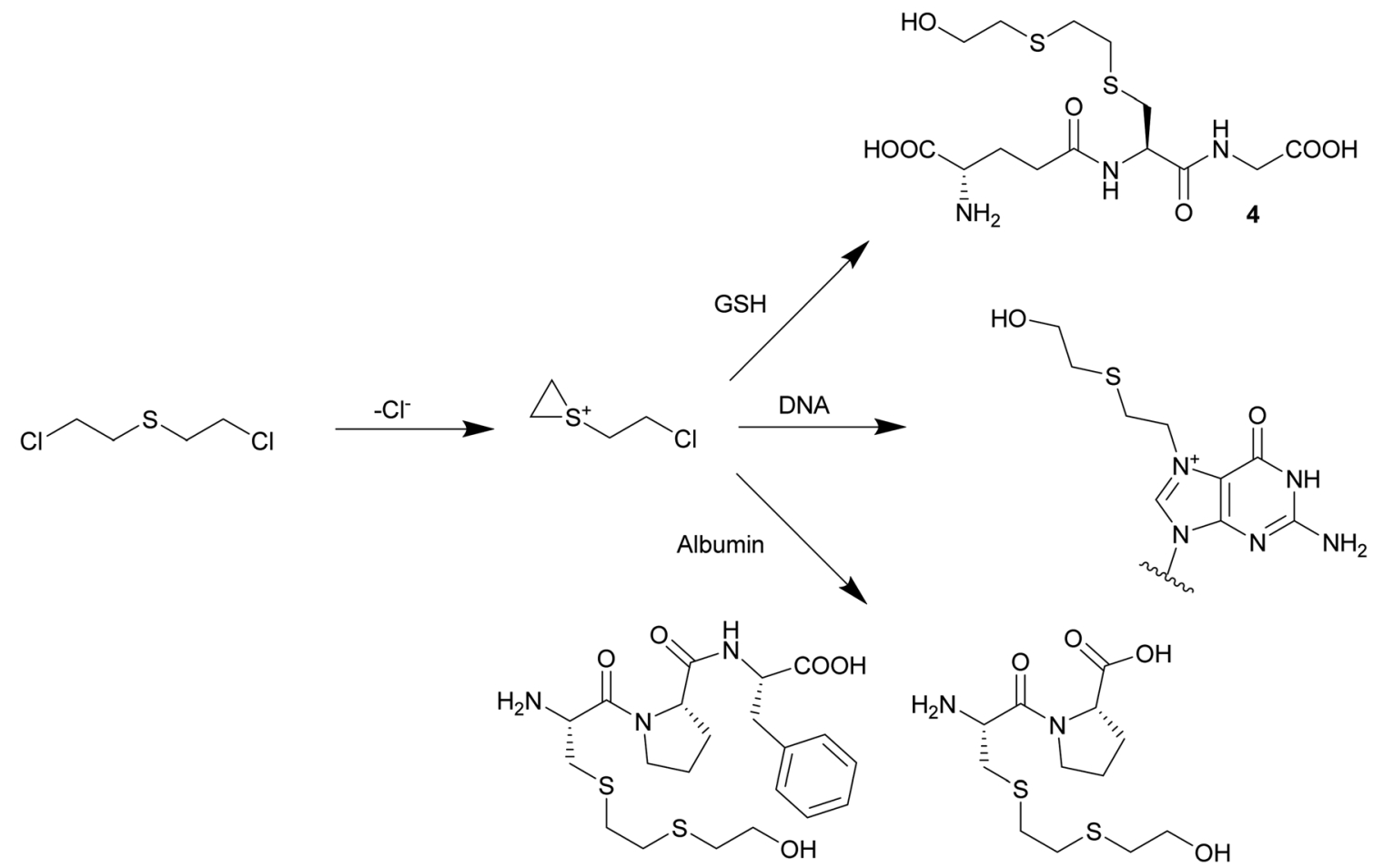

Scheme 1 Formation of the reactive episulfonium ion and examples of bioadducts formed: S-HETE-glutathione, HETE-N7-guanine and $\mathrm{C}(\mathrm{HETE}) \mathrm{P}$ or $\mathrm{C}(\mathrm{HETE}) \mathrm{PF}$, peptides of an albumin digest. ${ }^{6}$

detoxification and elimination of radicals, heavy metals and alkylating agents. GSH appears in high concentration in the liver ( $5 \mathrm{mM})$, but it is also transported into the blood stream $(1$ $\mathrm{mM}) .{ }^{11} \mathrm{GSH}$ is involved in the degradation and excretion of SM by the glutathione/ $\beta$-lyase pathway. ${ }^{12}$ Recently, several GSH-SM adducts were identified in in vitro tests. Black observed $S$-HETEGSH in human blood incubated with SM. ${ }^{10 a}$ Siegert observed the same adduct after direct treatment of GSH with SM. ${ }^{13}$ Halme incubated liver cytosol media in a phosphate buffer with SM and discovered the formation of $S$-HETE-GSH, GSH-ETE-GSH and 2-((2-(S-glutathionyl)ethyl)thio)ethyl phosphate. However, the last adduct might be formed due to reaction with the buffer phosphate. ${ }^{14}$ The above mentioned GSH-SM adducts were all detect by LC-MS.

The high concentration of GSH in the body and its affinity to react with SM makes the resulting adducts attractive candidates as biomarkers. However, none of these adducts have ever been isolated and characterized by analytical techniques other than LC-MS/MS. We herein present the synthesis and characterization of $S$-HETE-GSH and GSH-ETE-GSH which will help to

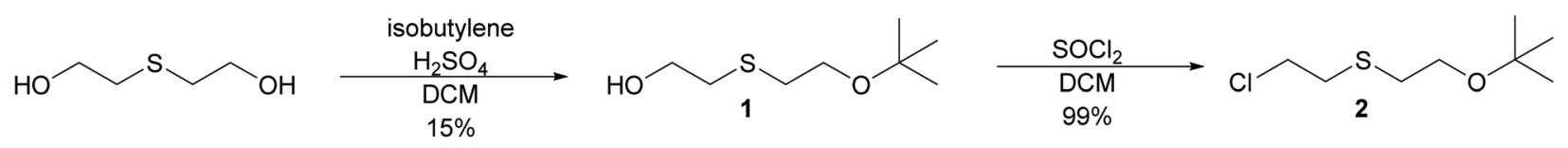

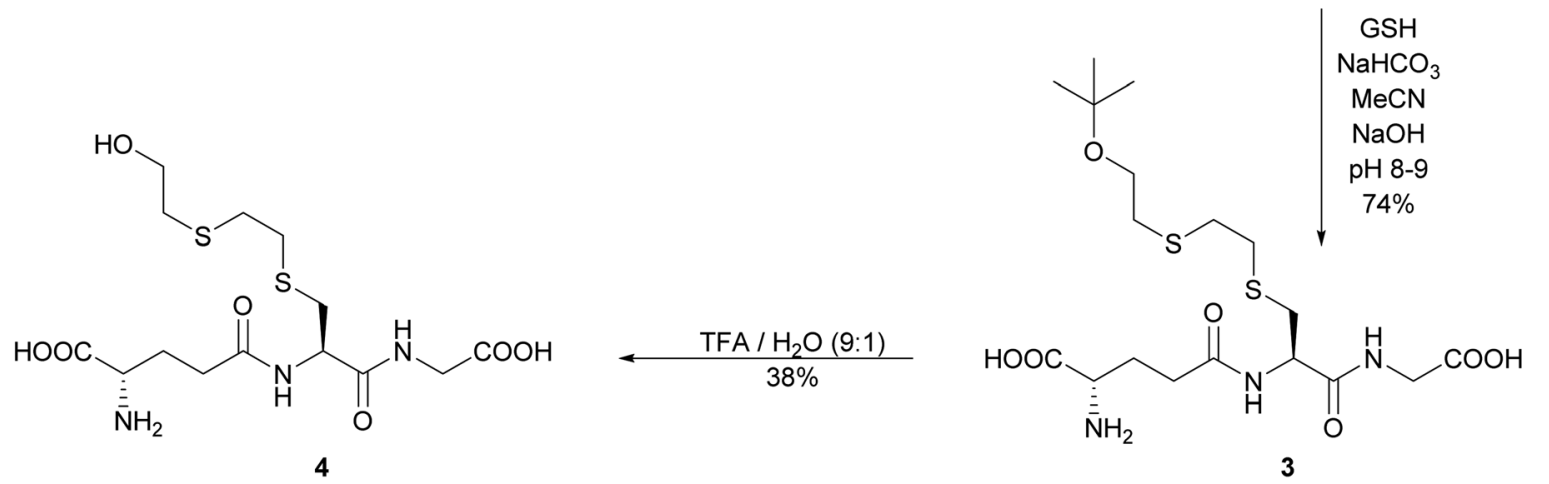

Scheme 2 Synthesis pathway of S-HETE-GSH 4 by alkylation of glutathione. 


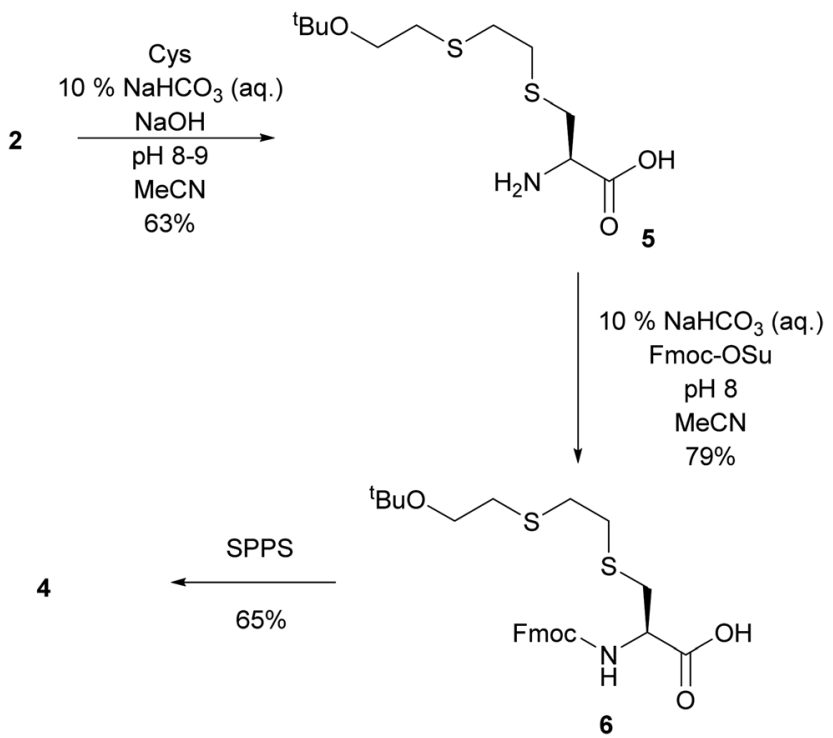

Scheme 3 Synthesis of S-HETE-GSH 4 by SPPS.

determine their potential as biomarkers. Further, we present the synthesis of the potential bioadducts bis-O-HETE-GSH and $O$-HETE-GSH which so far have never been observed. Having these compounds available as references might support further analytical work to establish new biomarkers for the intoxication with SM.

\section{Results and discussion}

\section{Synthesis of $S$-HETE-GSH 4}

The initial strategy investigated to synthesize $S$-HETE-GSH 4 was to alkylate GSH with the protected half mustard $t$ BuOETECl 2. The alkylating agent was prepared by protecting one of the hydroxyl groups of thiodiglycol (TDG) with a $t$ Bu-protecting group following a modified procedure of Noort. ${ }^{15}$ Isobutylene was bubbled through a solution of TDG and $\mathrm{H}_{2} \mathrm{SO}_{4}$ in DCM to yield $t$ BuOETEOH 1 . While the yield remained modest, yield and purity increased from $9 \%$ to $15 \%$ and from $>90 \%$ to $>98 \%$ respectively.
The $\mathrm{OH}$ group of $\mathbf{1}$ was then replaced by $\mathrm{Cl}$ by slow addition of thionyl chloride, which yielded $t$ BuOETECl 2 in high yield $(99 \%)$ and purity. ${ }^{15}$

GSH was alkylated with 2 under slightly basic conditions. ${ }^{15}$ The resulting $S$-tBuOETE-GSH 3 was purified by reversed phase flash chromatography and obtained in good yield and purity.

Several conditions were tested to cleave the tert-butyl ether 3 . Hydrolysis with phosphoric acid led to acceptable yield, however, the acid showed to be inseparable from the product. ${ }^{16}$ The use of Amberlyst 15 gave low yield and purity. ${ }^{17}$ The best result was obtained by using $90 \%$ TFA in aqueous solution. Some epimerization occurred, but the diastereomers could be separated, and $S$-HETE-GSH 4 was obtained in 38\% yield and $95 \%$ purity (Scheme 2 ).

As an alternative, a building-block approach was investigated in which cysteine was first alkylated and then used in solidphase-peptide-synthesis (SPPS). L-Cysteine was alkylated with 2 using the same procedure which was previously used to alkylate GSH. $S$-tBuOETE-Cys 5 was obtained in 63\% yield and very high purity. In the subsequent step the amine function of 5 was protected with Fmoc-OSu to give Fmoc-Cys(ETEOtBu)-OH $6 .{ }^{18}$ SPPS was performed on preloaded Gly-2-CT polystyrene resin and DIC/Oxyma were used as coupling agents. In the Fmoc-deprotection steps $20 \%$ piperidine in DMF was used. Coupling of 6 proved to be slow and its reaction time needed to be increased to $3 \mathrm{~h}$. Cleavage from the resin and deprotection were achieved with a cocktail consisting of TFA : TIS : $\mathrm{H}_{2} \mathrm{O}$ $(95: 2.5: 2.5)$. After purification by precipitation in cold ether and subsequent flash chromatography 4 was obtained in $65 \%$ yield and $>97 \%$ purity (Scheme 3 ).

With the direct alkylation approach 4 was obtained in two steps from GSH with $28 \%$ yield and $>95 \%$ purity. The buildingblock approach achieved $36 \%$ yield ( $>97 \%$ purity) in three steps from L-cysteine. The building-block pathway is recommended since it provides the reference material $\mathbf{4}$ in better overall yield and purity.

\section{Synthesis of GSH-ETE-GSH 7}

Another compound, which has been observed in in vitro biological assays but has never been isolated, is the adduct

Table 1 Coupling conditions for the synthesis of bis-O-HETE-N,S-Boc-GSH 12

\begin{tabular}{|c|c|c|c|c|c|c|c|}
\hline Entry & Coupling Agents & Bases & $T /{ }^{\circ} \mathrm{C}$ & $t / \mathrm{h}$ & Equiv. TDG & Yield/\% & Purity/\% (H NMR) \\
\hline 1 & EDC & - & $0^{\circ} \mathrm{C}->$ r.t. & 24 & 13 & 19 & 95 \\
\hline 2 & EDC & - & $0^{\circ} \mathrm{C}->$ r.t. & 22 & 26 & 13 & 50 \\
\hline 3 & $\mathrm{EDC} / \mathrm{HOBt}$ & - & $0^{\circ} \mathrm{C}->$ r.t. & 22 & 26 & 50 & 70 \\
\hline 4 & EDC/HOBt & DMAP & $0{ }^{\circ} \mathrm{C}->$ r.t. & 22 & 26 & 55 & 70 \\
\hline 5 & $\mathrm{EDC} / \mathrm{HOBt}$ & TEA & $0{ }^{\circ} \mathrm{C}->$ r.t. & 22 & 26 & 40 & 57 \\
\hline 6 & EDC/HOBt & DMAP/TEA & $0{ }^{\circ} \mathrm{C}->$ r.t. & 22 & 26 & 40 & 59 \\
\hline 7 & EDC & DMAP & $0{ }^{\circ} \mathrm{C}->$ r.t. & 22 & 26 & 34 & 54 \\
\hline 8 & EDC & DMAP/TEA & $0^{\circ} \mathrm{C}->$ r.t. & 22 & 26 & 24 & 63 \\
\hline 9 & EDC & TEA & $0{ }^{\circ} \mathrm{C}->$ r.t. & 22 & 26 & 7 & 38 \\
\hline 10 & $\mathrm{EDC} / \mathrm{HOBt}^{a}$ & DMAP & $0{ }^{\circ} \mathrm{C}->$ r.t. & 22 & 26 & 69 & 68 \\
\hline
\end{tabular}

${ }^{a}$ Reaction conducted under inert atmosphere. 
<smiles>CC(C)C[C@H](N)C(=O)O</smiles>

Scheme 4 Dimerization of two glutathione molecules with sulfur mustard as linker.<smiles>CC[C@H](NC(=O)CC[C@H](N)C(=O)OCCSCCO)C(=O)NCC(=O)OCCSCCO</smiles>

Scheme 5 Synthesis of bis-O-HETE-GSH 8.

consisting of two GSH linked by a sulfur mustard moiety via their thiol functions. Indeed, when a twofold excess of GSH reacted under slightly basic conditions with one equivalent of sulfur mustard, GSH-ETE-GSH 7 was formed. The reaction proceeded slowly, but after five days 7 could be isolated in $65 \%$ yield in $85 \%$ purity. The impurity was identified as residual acetonitrile (Scheme 4).

\section{Synthesis of bis-O-HETE-GSH 8}

The bioadducts bis-O-HETE-GSH 8, $O$-HETE-GSH 9 and GSH$O$-HETE 10 have never been observed. However, SM adducts of glutamic acid and aspartic acid have been observed in vitro, after SM reacted with their side chain acid groups. ${ }^{10 a}$ Therefore it could be envisageable that the adducts $\mathbf{8 , 9}$ and $\mathbf{1 0}$ would be formed as potential biomarkers. Both amine and thiol functionalities of GSH were protected in the presence of $\mathrm{Boc}_{2} \mathrm{O}$ to increase its solubility in organic solvents. ${ }^{19}$ Protected 11 still contained $S$-Boc and $N$-Boc monoprotected GSH as minor byproducts. 11 was observed as two diastereomers in a $1: 1$ ratio. Epimerization occurred at the cysteine moiety due to the basic conditions of the coupling. Several conditions to esterify 11 with excess of TDG were screened (Table 1). Best results for the coupling were obtained using EDC, HOBt and DMAP under inert atmosphere (Table 1, entry 10). However, the bis-O-HETE$N, S$-Boc-GSH adduct 12 could only be obtained in moderate purity. It was engaged without further purification in the subsequent deprotection step using a solution of TFA, TFE and water. While high yield was achieved, the final product 8 could not be separated from a side product which was identified as the tert-butyl thioether of $\mathbf{8}$. Neither could the diastereoisomers be separated. This resulted in reduced purity of $>75 \%$ (Scheme 5).

\section{Synthesis $O$-HETE-GSH}

In the attempt to synthesize the mono-O-HETE-GSH adducts 9 and 10 (Fig. 1), 11 was subjected to the coupling conditions of Table 1, entry 4, but only one equivalent of TDG was used. LCHRMS analysis of the resulting product mixture revealed that ca. $70 \%$ corresponded to either one of the two possible mono- $O$ HETE- $N, S$-Boc-GSH compounds, while $c a$. $11 \%$ corresponded to the bis-O-HETE- $N, S$-Boc-GSH 12 (data not shown). The mixture could not be separated. The experiment showed that, as expected, there was no selectivity between the two C-termini of $\mathbf{1 1}$.

Therefore, a building-block approach to synthesize $\mathbf{9}$ was investigated instead. Commercially available Boc-Glu(OFm)-<smiles>N[C@@H](CCC(=O)N[C@@H](CS)C(=O)NCC(=O)O)C(=O)OCCSCCO</smiles><smiles>N[C@@H](CCC(=O)NC(CS)C(=O)NCC(=O)OCCSCCO)C(=O)O</smiles>

Fig. 1 The two possibilities for O-alkylated GSH: O-HETE-GSH 9 and GSH-O-ETEH 10. 


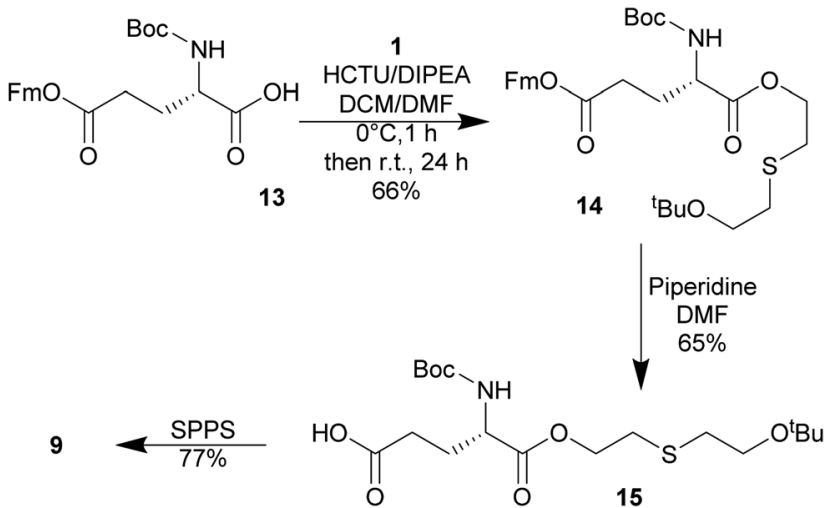

Scheme 6 Synthesis of O-HETE-GSH 9 using a building-block strategy.

$\mathrm{OH} 13$ was esterified with 1 using HCTU/DIPEA which gave Boc$\mathrm{Glu}(\mathrm{OFm})$-OETEO $t \mathrm{Bu}$ 14. The Fm group was selectively cleaved with $20 \%$ piperidine in DMF giving Boc-Glu(OH)-O-ETEO $t$ Bu 15 in $68 \%$ yield and good purity. 15 was used in SPPS to give 9 in $77 \%$ yield and $>90 \%$ purity (Scheme 6 ). The synthesis of 10 was not attempted.

\section{Conclusion}

Several synthesis strategies were explored to produce sulfur mustard-glutathione adducts as potential biomarkers for retrospective validation of exposure to this blistering agent. $S$ HETE-GSH 4 was successfully synthesized. Two pathways towards 4 were investigated. The direct alkylation of GSH with 2 and subsequent deprotection led to $28 \%$ overall yield from GSH and $>95 \%$ purity. However, better yield and purity were obtained when using a building-block approach and SPPS to construct the final peptide. While requiring an additional step, this route yielded $36 \%$ overall yield from Fmoc-Cys-OH and $>97 \%$ purity. It is recommended to use the building-block pathway to obtain $\mathbf{4}$, since the reference material can be obtained in better overall yield and purity.

The dimer GSH-ETE-GSH 7 was obtained in one step by condensing GSH with sulfur mustard.

The potential biomarker bis-O-HETE-GSH 8 was synthesized directly from the reaction of SM with GSH. While 8 was only obtained in moderate purity, the characterization data will help to investigate its presence in future in vitro and in vivo screenings.

Using the protected precursor Boc-Glu(OH)-O-ETEOtBu 15 in SPPS allowed the synthesis of the mono-O-HETE-GSH derivative 9 with $77 \%$ yield and $>90 \%$ purity in three steps.

\section{Experimental part}

Unless otherwise stated, all reagents were purchased from Sigma-Aldrich and were used without further purification. Glutathione was obtained from Iris Biotech. Deuterated solvents were purchased from Armar AG and Cambridge Isotope Laboratories, Inc. Boc-Glu(OFm)-OH was purchased from Bachem. Sulfur mustard was synthesized and provided by Spiez Laboratory. CAUTION: sulfur mustard is a schedule 1 chemical and is highly toxic. Adequate protection is needed and appropriate safety measures have to be taken when handling this compound.

Thin layer chromatography (TLC) was performed on silica gel 60 F-254 pre-coated aluminum sheets thin layer chromatography plates and silica gel RP-18 F-254S pre-coated aluminum sheets TLC plates from Merck.

Reaction monitoring by mass analysis was done by direct injection into a Dalton Mass Detector (ESI) from Biotage.

Flash column chromatography was carried out with an Isolera One system coupled with a Dalton Mass Detector from Biotage. Biotage SNAP Ultra cartridges $(10 \mathrm{~g}, 25 \mathrm{~g}, 50 \mathrm{~g}$ and 100 $\mathrm{g}$ ) and Biotage SNAP Ultra C18 cartridges (12 g, $30 \mathrm{~g}$ and $60 \mathrm{~g}$ ) were used.

SPPS was performed on an Initiator+ Alstra automated peptide-synthesizer from Biotage.

LC-HRMS (ESI) analyses were done on an Agilent Technologies 1290 Infinity LC System instrument with a Bruker Daltonics maXis UHR QTof $4 \mathrm{G}$ MS. As a column the Sigma-Aldrich Discovery HS C18 $(150 \mathrm{~mm} \times 2.1 \mathrm{~mm}$, particle size $5 \mu \mathrm{m})$ was used. As eluents $\mathrm{H}_{2} \mathrm{O}$ with $5 \mathrm{mM} \mathrm{NH}_{4} \mathrm{Ac}$ and $\mathrm{MeOH}$ with $5 \mathrm{mM}$ $\mathrm{NH}_{4} \mathrm{Ac}$ were used with a flow-rate of $0.6 \mathrm{~mL} \mathrm{~min}^{-1}$.

GC-MS (EI) analyses were performed on an Agilent Technologies 7890A instrument coupled with an Agilent Technologies 5975C inert MSD. The measurements were performed with the HP-1701 $(30 \mathrm{~m} \times 0.25 \mathrm{~mm} \times 0.25 \mu \mathrm{m}, 14 \%$ cyanopropylphenyl/86\% PDMS) high resolution gas chromatography column using a temperature program $\left(40{ }^{\circ} \mathrm{C}\right.$ for $3 \mathrm{~min}$, $13{ }^{\circ} \mathrm{C} \mathrm{min}{ }^{-1}$ until $280{ }^{\circ} \mathrm{C}$ and $280{ }^{\circ} \mathrm{C}$ for $3.54 \mathrm{~min}$ ). The injector and the detector temperatures were $220{ }^{\circ} \mathrm{C}$ and $250{ }^{\circ} \mathrm{C}$, respectively. The splitless injection mode was used to inject volumes of $1 \mu \mathrm{L}\left(c=0.5 \mathrm{mg} \mathrm{mL}^{-1}\right)$. Helium was used as carrier gas $\left(1 \mathrm{~mL} \mathrm{~min}^{-1}\right)$.

NMR spectra were recorded on a Bruker Avance III HD 400 $\mathrm{MHz}$ Nano Bay spectrometer in $\mathrm{CDCl}_{3}$, DMSO-d $\mathrm{d}_{6}$, MeOD or $\mathrm{D}_{2} \mathrm{O}$. ${ }^{1} \mathrm{H}$ NMR spectra were measured at $400 \mathrm{MHz}$ and ${ }^{13} \mathrm{C} \mathrm{NMR}$ spectra at $100 \mathrm{MHz}$. Chemical shifts are expressed as parts per million $(\delta)$ using TMS or residual solvent protons as internal standards. Coupling constants $(J)$ are reported in Hz. Splitting patterns are described as $\mathrm{s}$ (singlet), br. (broad singlet), $\mathrm{d}$ (doublet), dd (double doublet), dt (double triplet), $\mathrm{t}$ (triplet), $\mathrm{td}$ (triple doublet), q (quartet) and $\mathrm{m}$ (multiplet).

IR spectra were measured on a Bruker Tensor 27 and a Jasco FT/IR-4100 spectrometer.

Purities were assessed by NMR.

\section{2-(2-(tert-Butoxy)ethylthio)ethanol, $t$ BuOETEOH 1}

Thiodiglycol (4.60 mL, $45 \mathrm{mmol}, 1$ equiv.) was dissolved in DCM (45 mL) and $\mathrm{H}_{2} \mathrm{SO}_{4}(0.27 \mathrm{~mL}, 5 \mathrm{mmol})$ was added. The reaction mixture was cooled to $4{ }^{\circ} \mathrm{C}$ and isobutylene was passed through the solution for $1.5 \mathrm{~h}$. The solution was stirred for $72 \mathrm{~h}$ at room temperature. The reaction was monitored by GC-MS. The mixture was washed with $\mathrm{H}_{2} \mathrm{O}(3 \times 25 \mathrm{~mL})$ and sat. aq. $\mathrm{NaHCO}_{3}$ $(1 \times 15 \mathrm{~mL})$. The organic layer was dried over $\mathrm{MgSO}_{4}$ and the 
solvent was evaporated under reduced pressure affording a colorless oil (1.18 g, $7 \mathrm{mmol}, 15 \%$, purity > 98\%).

${ }^{1} \mathrm{H}$ NMR $\left(400 \mathrm{MHz}, \mathrm{CDCl}_{3}\right) \delta: 3.77\left(\mathrm{dt}, J=6 \mathrm{~Hz}, 2 \mathrm{H}, \mathrm{CH}_{2} \mathrm{OH}\right)$, $3.55\left(\mathrm{t}, J=7 \mathrm{~Hz}, 2 \mathrm{H}, \mathrm{CH}_{2} \mathrm{O} t \mathrm{Bu}\right), 3.16(\mathrm{t}, J=7 \mathrm{~Hz}, 1 \mathrm{H}, \mathrm{OH}), 2.78(\mathrm{t}$, $\left.J=6 \mathrm{~Hz}, 2 \mathrm{H}, \mathrm{CH}_{2} \mathrm{CH}_{2} \mathrm{OH}\right), 2.73\left(\mathrm{t}, J=7 \mathrm{~Hz}, 2 \mathrm{H}, \mathrm{CH}_{2} \mathrm{CH}_{2} \mathrm{O} t \mathrm{Bu}\right)$, $1.22\left(\mathrm{~s}, 9 \mathrm{H}, \mathrm{C}\left(\mathrm{CH}_{3}\right)_{3}\right) \mathrm{ppm}$.

${ }^{13} \mathrm{C}$ NMR $\left\{{ }^{1} \mathrm{H}\right\}\left(100 \mathrm{MHz}, \mathrm{CDCl}_{3}\right) \delta: 73.6\left(\mathrm{C}\left(\mathrm{CH}_{3}\right)_{3}\right), 62.1$ $\left(\mathrm{CH}_{2} \mathrm{OtBu}\right), 61.4\left(\mathrm{CH}_{2} \mathrm{OH}\right), 36.3\left(\mathrm{CH}_{2} \mathrm{CH}_{2} \mathrm{OH}\right), 32.6\left(\mathrm{CH}_{2} \mathrm{CH}_{2}-\right.$ $\mathrm{O} t \mathrm{Bu}), 27.5\left(\mathrm{C}\left(\mathrm{CH}_{3}\right)_{3}\right) \mathrm{ppm}$.

GCMS (EI) RT: $13.0 \mathrm{~min}, \mathrm{~m} / z:[\mathrm{M}]^{+} 178(0.2 \%),\left[\mathrm{M}^{+}-\mathrm{H}_{2} \mathrm{O}\right]$ $160(9 \%),\left[\mathrm{M}^{+}-\mathrm{OC}\left(\mathrm{CH}_{3}\right)_{3}\right] 105(33 \%),\left[\mathrm{M}^{+}-\mathrm{CHOC}\left(\mathrm{CH}_{3}\right)_{3}\right] 92$ (30\%), $\left[\mathrm{HSCH}_{2} \mathrm{CH}_{2}\right]^{+} 61(17 \%),\left[\mathrm{C}\left(\mathrm{CH}_{3}\right)_{3}\right]^{+} 57$ (100\%).

FTIR (neat): 3456, 3419, 3401, 3374, 2973, 2929, 2872, 2254, 2242, 2217, 2198, 2176, 1959, 1947, 1654, 1592, 1473, 1391, 1363, 1284, 1260, 1233, 1194, 1069, 1045, 1016, 883, 826, 777, $692 \mathrm{~cm}^{-1}$.

\section{2-(2-(tert-Butoxy)ethylthio)ethyl chloride, $t$ BuOETECl 2}

1 (1.45 g, $8 \mathrm{mmol}$ ) was dissolved in DCM (15 mL) and a solution of $\mathrm{SOCl}_{2}(830 \mu \mathrm{L}, 11 \mathrm{mmol}, 1.4$ equiv. $)$ in DCM $(10 \mathrm{~mL})$ was added dropwise at $0{ }^{\circ} \mathrm{C}$. The reaction was monitored by GC-MS, and after complete conversion of the starting material, the solvent was evaporated under reduced pressure. The product was obtained as a yellowish oil $(1.58 \mathrm{mg}, 8 \mathrm{mmol}, 99 \%$, purity > $98 \%)$.

${ }^{1} \mathrm{H}$ NMR $\left(400 \mathrm{MHz}, \mathrm{CDCl}_{3}\right) \delta: 3.67\left(\mathrm{t}, J=7.8 \mathrm{~Hz}, 2 \mathrm{H}, \mathrm{CH}_{2} \mathrm{Cl}\right)$, $3.55\left(\mathrm{t}, J=6.5 \mathrm{~Hz}, 2 \mathrm{H}, \mathrm{CH}_{2} \mathrm{OtBu}\right), 2.94\left(\mathrm{t}, J=8.0 \mathrm{~Hz}, 2 \mathrm{H}, \mathrm{CH}_{2^{-}}\right.$ $\left.\mathrm{CH}_{2} \mathrm{Cl}\right), 2.70\left(\mathrm{t}, 2 \mathrm{H}, J=6.5 \mathrm{~Hz}, \mathrm{CH}_{2} \mathrm{CH}_{2} \mathrm{O} t \mathrm{Bu}\right), 1.20(9 \mathrm{H}, \mathrm{s}$, $\left.\mathrm{C}\left(\mathrm{CH}_{3}\right)_{3}\right)$ ppm.

${ }^{13} \mathrm{C}$ NMR $\left\{{ }^{1} \mathrm{H}\right\}\left(100 \mathrm{MHz}, \mathrm{CDCl}_{3}\right) \delta: 73.3\left(\mathrm{C}\left(\mathrm{CH}_{3}\right)_{3}\right), 62.2$ $\left(\mathrm{CH}_{2} \mathrm{OtBu}\right), 43.2\left(\mathrm{CH}_{2} \mathrm{Cl}\right), 34.8\left(\mathrm{CH}_{2} \mathrm{CH}_{2} \mathrm{Cl}\right), 33.0\left(\mathrm{CH}_{2} \mathrm{CH}_{2} \mathrm{O} t \mathrm{Bu}\right)$, $27.5\left(\mathrm{C}\left(\mathrm{CH}_{3}\right)_{3}\right) \mathrm{ppm}$.

GC-MS (EI) RT: $12.8 \mathrm{~min}, m / z:\left[\mathrm{M}^{+}-\mathrm{HCl}\right] 160$ (15\%), [ $\mathrm{M}^{+}-$ $\left.\mathrm{OC}\left(\mathrm{CH}_{3}\right)_{3}\right] 123$ (31\%), $\left[\mathrm{M}^{+}-\mathrm{CHOC}\left(\mathrm{CH}_{3}\right)_{3}\right] 110 \quad(32 \%)$, $\left[\mathrm{HSHCH}_{2} \mathrm{CH}_{2}\right]^{+} 61(14 \%),\left[\mathrm{C}\left(\mathrm{CH}_{3}\right)_{3}\right]^{+} 57(100 \%)$.

FTIR (neat): 3789, 3658, 2904, 1622, 1409, 1252, 1072, 886, $678 \mathrm{~cm}^{-1}$.

\section{$S$-(2-(2-(tert-Butoxy)ethylthio)ethyl)glutathione, $S$-tBuOETE- GSH 3}

To a solution of GSH ( $470 \mathrm{mg}, 1.53 \mathrm{mmol}, 1$ equiv.) in sat. aq. $\mathrm{NaHCO}_{3}(10 \mathrm{~mL})$ was added portionwise a solution of $2(400 \mathrm{mg}$, $2.03 \mathrm{mmol}, 1.3$ equiv.) in MeCN (10 mL). The $\mathrm{pH}$ of the solution was kept at $8-9$ by the addition of aq. $\mathrm{NaOH}(0.1 \mathrm{M})$. The mixture was stirred for $2 \mathrm{~h}$ and monitored by MS. The mixture was washed with DCM $(3 \times 12 \mathrm{~mL})$ and the aqueous layer was concentrated under reduced pressure. The crude product was purified by reversed phase flash chromatography (SNAP Ultra $\mathrm{C} 1860 \mathrm{~g}, \mathrm{H}_{2} \mathrm{O} / \mathrm{MeCN}$ from $0 \%$ to $\left.100 \% \mathrm{MeCN}\right)$. The product was obtained as a colorless solid (532 mg, $1.14 \mathrm{mmol}, 74 \%$, purity > $98 \%)$.

${ }^{1} \mathrm{H}$ NMR (400 MHz, D $\left.\mathrm{O}\right) \delta: 4.61-4.58\left(\mathrm{~m}, 1 \mathrm{H}, \mathrm{Cys} \mathrm{CHCH}_{2}\right)$, $3.78\left(\mathrm{~d}, J=8 \mathrm{~Hz}, 2 \mathrm{H}\right.$, Gly $\left.\mathrm{CH}_{2} \mathrm{COOH}\right), 3.65(\mathrm{t}, J=6 \mathrm{~Hz}, 2 \mathrm{H}$, $\mathrm{CH}_{2} \mathrm{O} t \mathrm{Bu}$ ), 3.46 (t, $J=7 \mathrm{~Hz}, 1 \mathrm{H}$, Glu $\mathrm{CHNH}_{2}$ ), 3.11 (dd, $J=5 \mathrm{~Hz}, J$ $=14 \mathrm{~Hz}, 1 \mathrm{H}$, Cys $\left.\mathrm{CHCH}_{2} \mathrm{~S}\right), 2.89(\mathrm{dd}, J=9 \mathrm{~Hz}, J=14 \mathrm{~Hz}, 1 \mathrm{H}$, Cys $\left.\mathrm{CHCH}_{2} \mathrm{~S}\right), 2.85\left(\mathrm{~m}, 4 \mathrm{H}, \mathrm{SCH}_{2} \mathrm{CH}_{2} \mathrm{~S}\right), 2.74(\mathrm{t}, J=6 \mathrm{~Hz}, 2 \mathrm{H}$,
$\mathrm{CH}_{2} \mathrm{CH}_{2} \mathrm{O} t \mathrm{Bu}$ ), 2.50-2.40 (m, 2H, Glu $\mathrm{CH}_{2} \mathrm{CH}_{2} \mathrm{CONH}$ ), 2.08-1.86 (m, 2H, Glu $\left.\mathrm{CH}_{2} \mathrm{CH}_{2} \mathrm{CONH}\right), 1.24\left(\mathrm{~s}, 9 \mathrm{H}, \mathrm{C}\left(\mathrm{CH}_{3}\right)_{3}\right) \mathrm{ppm}$.

${ }^{13} \mathrm{C}$ NMR $\left\{{ }^{1} \mathrm{H}\right\}\left(100 \mathrm{MHz}, \mathrm{D}_{2} \mathrm{O}\right) \delta: 179.2(C \mathrm{O}), 176.2(\mathrm{CO})$, 175.8 (CO), $171.9(\mathrm{CO}), 75.2\left(C\left(\mathrm{CH}_{3}\right)_{3}\right), 61.0\left(\mathrm{CH}_{2} \mathrm{OtBu}\right), 55.0$ (Cys $\mathrm{CHCH}_{2}$ ), 53.1 (Glu $\mathrm{CHNH}_{2}$ ), 43.4 (Gly $\left.\mathrm{CH}_{2} \mathrm{COOH}\right), 32.9\left(\mathrm{CH}_{2}-\right.$ $\mathrm{CH}_{2} \mathrm{O}$ Bu), $32.0\left(\mathrm{Cys} \mathrm{CHCH}_{2} \mathrm{~S}\right), 31.6$ \& $31.5\left(\mathrm{SCH}_{2} \mathrm{CH}_{2} \mathrm{~S}\right), 31.3$ (Glu $\mathrm{CH}_{2} \mathrm{CH}_{2} \mathrm{CONH}$ ), 29.1 (Glu $\mathrm{CH}_{2} \mathrm{CH}_{2} \mathrm{CONH}$ ), 26.6 $\left(\mathrm{C}\left(\mathrm{CH}_{3}\right)_{3}\right)$ ppm.

HRMS (ESI/Q-TOF) $m / z[\mathrm{M}+\mathrm{H}]^{+}$calcd for $\mathrm{C}_{18} \mathrm{H}_{34} \mathrm{~N}_{3} \mathrm{O}_{7} \mathrm{~S}_{2}$ 468.1832, found: 468.1822 .

FTIR (neat): 2975, 1642, 1586, 1390, 1361, 1307, 1259, 1233, 1196, 1092, 1072, 1018, 911, 883, 824, $641 \mathrm{~cm}^{-1}$.

Mp $196{ }^{\circ} \mathrm{C}$ (degradation).

\section{S-(2-(2-(Hydroxy)ethylthio)ethyl)glutathione, S-HETE-GSH 4 by alkylation of GSH}

A solution of $90 \%$ aq. TFA was slowly added to 3 (347 mg, $0.74 \mathrm{mmol}, 1$ equiv.) at $0{ }^{\circ} \mathrm{C}$. The reaction mixture was then stirred at room temperature for $2 \mathrm{~h}$. TFA and water were evaporated under reduced pressure and the crude product was purified by flash chromatography (SNAP Ultra $25 \mathrm{~g}, \mathrm{DCM} / \mathrm{MeOH}$ from $21 \%$ to $100 \% \mathrm{MeOH})$. The product was obtained as a viscous colorless oil (116 mg, $0.28 \mathrm{mmol}, 38 \%$, purity $>95 \%$ ).

${ }^{1} \mathrm{H}$ NMR $\left(400 \mathrm{MHz}, \mathrm{D}_{2} \mathrm{O}\right) \delta: 4.59(\mathrm{dd}, J=4 \mathrm{~Hz}, J=8 \mathrm{~Hz}, 1 \mathrm{H}$, Cys $\mathrm{CHCH}_{2}$ ), 4.06 (t, $J=6 \mathrm{~Hz}, 1 \mathrm{H}$, Glu $\mathrm{CHNH} \mathrm{N}_{2}$ ), 4.02 (s, 2H, Gly $\left.\mathrm{CH}_{2} \mathrm{COOH}\right), 3.75\left(\mathrm{t}, J=6 \mathrm{~Hz}, 2 \mathrm{H}, \mathrm{CH}_{2} \mathrm{OH}\right), 3.09(\mathrm{dd}, J=6 \mathrm{~Hz}, J=$ $14 \mathrm{~Hz}, 1 \mathrm{H}$, Cys $\mathrm{CHCH}_{2} \mathrm{~S}$ ), 2.90 (dd, $J=9 \mathrm{~Hz}, J=14 \mathrm{~Hz}, 1 \mathrm{H}$, Cys $\left.\mathrm{CHCH}_{2} \mathrm{~S}\right), 2.84\left(\mathrm{~s}, 4 \mathrm{H}, \mathrm{SCH}_{2} \mathrm{CH}_{2} \mathrm{~S}\right), 2.75\left(\mathrm{t}, J=6 \mathrm{~Hz}, 2 \mathrm{H}, \mathrm{CH}_{2}-\right.$ $\mathrm{CH}_{2} \mathrm{OH}$ ), 2.66-2.53 (m, 2H, Glu $\mathrm{CH}_{2} \mathrm{CH}_{2} \mathrm{CONH}$ ), 2.31-2.16 (m, $2 \mathrm{H}$, Glu $\left.\mathrm{CH}_{2} \mathrm{CH}_{2} \mathrm{CONH}\right) \mathrm{ppm}$.

${ }^{13} \mathrm{C}$ NMR $\left\{{ }^{1} \mathrm{H}\right\}\left(100 \mathrm{MHz}, \mathrm{D}_{2} \mathrm{O}\right) \delta: 174.5(C \mathrm{O}), 172.9(C \mathrm{O})$, 172.7 (CO), 172.2 (CO), $60.3\left(\mathrm{CH}_{2} \mathrm{OH}\right), 53.1\left(\mathrm{Cys}^{\mathrm{CHCH}}{ }_{2}\right), 52.3$ (Glu $\mathrm{CHNH}_{2}$ ), 41.1 (Gly $\left.\mathrm{CH}_{2} \mathrm{COOH}\right), 33.3\left(\mathrm{CH}_{2} \mathrm{CH}_{2} \mathrm{OH}\right), 32.7$ (Cys $\left.\mathrm{CHCH}_{2} \mathrm{~S}\right), 31.6$ \& $31.0\left(\mathrm{SCH}_{2} \mathrm{CH}_{2} \mathrm{~S}\right), 30.9$ (Glu $\left.\mathrm{CH}_{2} \mathrm{CH}_{2} \mathrm{CONH}\right)$, 25.5 (Glu $\mathrm{CH}_{2} \mathrm{CH}_{2} \mathrm{CONH}$ ) ppm.

HRMS (ESI/Q-TOF) $m / z[\mathrm{M}+\mathrm{H}]^{+}$calcd for $\mathrm{C}_{14} \mathrm{H}_{26} \mathrm{~N}_{3} \mathrm{O}_{7} \mathrm{~S}_{2}$ 412.1207, found: 412.1202.

FTIR (neat): 1671, 1640, 1616, 1602, 1589, 1556, 1526, 1511, 1412, 1400, 1353, 1308, 1233, 1202, 1132, 1066, 1047, 1041, 1010, 916, 909, 877, $657 \mathrm{~cm}^{-1}$.

\section{$S$-(2-((2-(tert-Butoxy)ethyl)thio)ethyl)cysteine, $S$ - $t$ BuOETE-Cys} 5

L-Cysteine (512 mg, $4 \mathrm{mmol}, 1$ equiv.) was dissolved in sat. aq. $\mathrm{NaHCO}_{3}(25 \mathrm{~mL})$. A solution of $2(1150 \mathrm{mg}, 6 \mathrm{mmol}, 1.5$ equiv.) in $\mathrm{MeCN}(25 \mathrm{~mL})$ was added portionwise over $30 \mathrm{~min}$. The $\mathrm{pH}$ of the reaction mixture was kept at 8-9 by addition of aq. $\mathrm{NaOH}$ $(0.1 \mathrm{M})$. The solution was stirred for $2 \mathrm{~h}$ at room temperature and monitored by TLC (DCM/MeOH, $7: 3$ ). The mixture was concentrated under reduced pressure and the crude product was purified by reversed phase flash chromatography (SNAP Ultra $\mathrm{C} 1860 \mathrm{~g}, \mathrm{H}_{2} \mathrm{O} / \mathrm{MeCN}$ from $0 \%$ to $\left.60 \% \mathrm{MeCN}\right)$. The product was obtained as a white powder $(755 \mathrm{mg}, 3 \mathrm{mmol}, 63 \%$, purity > 98\%).

${ }^{1} \mathrm{H}$ NMR (400 MHz, $\left.\mathrm{D}_{2} \mathrm{O}\right) \delta: 3.85(\mathrm{dd}, J=4.3 \mathrm{~Hz}, J=7.3 \mathrm{~Hz}$, $1 \mathrm{H}, \mathrm{CH}), 3.57$ (t, $\left.J=6.4 \mathrm{~Hz}, 2 \mathrm{H}, \mathrm{CH}_{2} \mathrm{O} t \mathrm{Bu}\right), 3.10-2.96(\mathrm{~m}, 2 \mathrm{H}$, 
$\mathrm{CHCH}_{2}$ ), $2.78\left(\mathrm{~s}, 4 \mathrm{H}, \mathrm{SCH}_{2} \mathrm{CH}_{2} \mathrm{~S}\right), 2.66\left(\mathrm{t}, J=6.4 \mathrm{~Hz}, 2 \mathrm{H}, \mathrm{CH}_{2^{-}}\right.$ $\left.\mathrm{CH}_{2} \mathrm{O} t \mathrm{Bu}\right), 1.15$ (s, 9H, $\left.\mathrm{C}\left(\mathrm{CH}_{3}\right)_{3}\right) \mathrm{ppm}$.

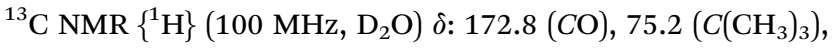
$60.9\left(\mathrm{CH}_{2} \mathrm{O}\right), 53.6(\mathrm{CH}), 32.0\left(\mathrm{SCH}_{2} \mathrm{CH}_{2} \mathrm{~S}\right), 31.5\left(\mathrm{SCH}_{2} \mathrm{CH}_{2} \mathrm{~S}\right), 31.3$ $\left(\mathrm{CHCH}_{2}\right), 31.1\left(\mathrm{CH}_{2} \mathrm{CH}_{2} \mathrm{OtBu}\right), 26.5\left(\mathrm{C}\left(\mathrm{CH}_{3}\right)_{3}\right) \mathrm{ppm}$.

HRMS (ESI/Q-TOF) $m / z[\mathrm{M}+\mathrm{H}]^{+}$calcd for $\mathrm{C}_{11} \mathrm{H}_{24} \mathrm{NO}_{3} \mathrm{~S}_{2}$ 282.1192, found: 282.1188 .

FTIR (neat): 3700，2973，2905，1588，1409，1255，1071, $886 \mathrm{~cm}^{-1}$.

\section{$N$-(((9H-Fluoren-9-yl)methoxy)carbonyl)-S-(2-((2-(tert-butoxy) ethyl)thio)ethyl)cysteine, Fmoc-Cys(ETEOtBu)-OH 6}

5 (1200 mg, 4 mmol, 1 equiv.) was dissolved in $\mathrm{H}_{2} \mathrm{O}(10 \mathrm{~mL}$ ) and a solution of aq. $\mathrm{Na}_{2} \mathrm{CO}_{3}(10 \%)$ was added until pH 8 . The solution was then cooled to $0{ }^{\circ} \mathrm{C}$ and a solution of Fmoc-OSu (2200 mg, $6 \mathrm{mmol}, 1.5$ equiv.) in $\mathrm{MeCN}(30 \mathrm{~mL}$ ) was added dropwise over $30 \mathrm{~min}$. The reaction mixture was stirred $1 \mathrm{~h}$ at $0{ }^{\circ} \mathrm{C}$ and at room temperature over night. The solvent was then removed under reduced pressure and $\mathrm{H}_{2} \mathrm{O}(15 \mathrm{~mL})$ was added. The solution was acidified to $\mathrm{pH} 2$ with a solution of $\mathrm{KHSO}_{4}$ $(5 \%)$ and extracted with EtOAc $(3 \times 45 \mathrm{~mL})$. The organic phases were combined and washed with brine $(20 \mathrm{~mL})$ and $\mathrm{H}_{2} \mathrm{O}(20$ $\mathrm{mL}$ ), dried over $\mathrm{Na}_{2} \mathrm{SO}_{4}$ and concentrated under reduced pressure. The crude product was purified by flash chromatography (SNAP Ultra $50 \mathrm{~g}$, hexane/EtOAc from $10 \%$ to $60 \%$ EtOAc). The product was obtained as a white solid $(1706 \mathrm{mg}, 4 \mathrm{mmol}, 79 \%$, purity $>95 \%$ ).

${ }^{1} \mathrm{H}$ NMR $\left(400 \mathrm{MHz}, \mathrm{CD}_{3} \mathrm{CN}\right) \delta: 7.87(\mathrm{~d}, J=7.5 \mathrm{~Hz}, 2 \mathrm{H}, \mathrm{Fmoc})$, 7.71 (d, $J=7.4 \mathrm{~Hz}, 2 \mathrm{H}, \mathrm{Fmoc}), 7.45$ (t, $J=7.4 \mathrm{~Hz}, 2 \mathrm{H}, \mathrm{Fmoc}), 7.37$ (t, $J=7.4 \mathrm{~Hz}, 2 \mathrm{H}, \mathrm{Fmoc}), 6.16$ (d, $J=7.9 \mathrm{~Hz}, 1 \mathrm{H}, \mathrm{NH}), 4.44-4.35$ (m, 3H, Fmoc), 4.28 (t, $J=6.8 \mathrm{~Hz}, 1 \mathrm{H}, \mathrm{Fmoc} \mathrm{CH}), 3.51(\mathrm{t}, J=$ $\left.6.5 \mathrm{~Hz}, 2 \mathrm{H}, \mathrm{CH}_{2} \mathrm{O} t \mathrm{Bu}\right), 3.12-2.87\left(\mathrm{~m}, 2 \mathrm{H}, \mathrm{C}(\mathrm{O}) \mathrm{CHCH}_{2}\right), 2.78(\mathrm{~s}$, $\left.4 \mathrm{H}, \mathrm{SCH}_{2} \mathrm{CH}_{2} \mathrm{~S}\right), 2.63\left(\mathrm{t}, J=6.5 \mathrm{~Hz}, 2 \mathrm{H}, \mathrm{CH}_{2} \mathrm{CH}_{2} \mathrm{O} t \mathrm{Bu}\right), 1.16(\mathrm{~s}$, 9H, $\left.\mathrm{C}\left(\mathrm{CH}_{3}\right)_{3}\right)$ ppm.

${ }^{13} \mathrm{C}$ NMR $\left\{{ }^{1} \mathrm{H}\right\}\left(100 \mathrm{MHz}, \mathrm{CD}_{3} \mathrm{CN}\right) \delta: 144.7$ (Fmoc), 141.7 (Fmoc), 128.3 (Fmoc), 127.8 (Fmoc), 125.8 (Fmoc), 120.6 (Fmoc), $73.5\left(\mathrm{C}\left(\mathrm{CH}_{3}\right)_{3}\right), 62.3\left(\mathrm{CH}_{2} \mathrm{O}\right), 54.5(\mathrm{C}(\mathrm{O}) \mathrm{CH}), 47.6(\mathrm{Fmoc} \mathrm{CH})$, $32.9 \quad\left(\mathrm{SCH}_{2} \mathrm{CH}_{2} \mathrm{~S}\right), \quad 32.7 \quad\left(\mathrm{SCH}_{2} \mathrm{CH}_{2} \mathrm{~S}\right), \quad 32.6 \quad\left(\mathrm{CHCH}_{2}\right)$, $27.3 \mathrm{C}\left(\mathrm{CH}_{3}\right)_{3} \mathrm{ppm}$.

HRMS (ESI/Q-TOF) $m / z[M+H]^{+}$calcd for $\mathrm{C}_{26} \mathrm{H}_{34} \mathrm{NO}_{5} \mathrm{~S}_{2}$ 504.1872, found: 504.1879.

FTIR (neat): 3701, 2972, 2362, 1723, 1636, 1530, 1447, 1205, $1075,74 \mathrm{~cm}^{-1}$.

\section{$S$-(2-(2-(Hydroxy)ethylthio)ethyl)glutathione, S-HETE-GSH 4} by SPPS

The synthesis of $S$-(HETE)-GSH 4 was performed by SPPS on a $0.2 \mathrm{mmol}$ scale. The preloaded resin H-Gly-2-ClTrt resin (0.182 g, loading $1.1 \mathrm{mmol} \mathrm{g}^{-1}$ ) was swelled with DMF (4.5 mL) over $2 \mathrm{~h}$ at room temperature. The resin was then mixed with 6 (428 mg, $0.8 \mathrm{mmol}, 4$ equiv.) in DMF $(1.35 \mathrm{~mL})$, DIC $(128 \mu \mathrm{L}$, $0.8 \mathrm{mmol}, 4$ equiv.) in DMF $(1.52 \mathrm{~mL})$ and Oxyma pure $(117 \mathrm{mg}$, $0.8 \mathrm{mmol}$, 4 equiv.) in DMF $(1.65 \mathrm{~mL})$. The reaction mixture was stirred for $3 \mathrm{~h}$ at room temperature. After DMF washes, a solution of $20 \%$ piperidine in DMF ( $4.5 \mathrm{~mL}, 90$ equiv.) was added twice, for $5 \mathrm{~min}$ and $15 \mathrm{~min}$ agitation respectively. After another washing step, Boc-Glu-OtBu (234 mg, $0.8 \mathrm{mmol}, 4$ equiv.) in DMF (1.5 mL), DIC (128 $\mu \mathrm{L}, 0.8 \mathrm{mmol}, 4$ equiv.) in DMF $(1.52 \mathrm{~mL})$ and Oxyma pure (117 mg, $0.8 \mathrm{mmol}, 4$ equiv.) in DMF $(1.65 \mathrm{~mL})$ were added to the resin. The reaction mixture was stirred again for $3 \mathrm{~h}$ at room temperature, followed by a pre-cleavage wash of the resin with DCM $(4 \times 9 \mathrm{~mL})$. An automated pre-cleavage wash with DCM $(4.5 \mathrm{~mL}), \mathrm{MeOH}(4.5 \mathrm{~mL})$ and DCM $(4.5 \mathrm{~mL})$ was then performed by the instrument. The resin was transferred into a new flask and the following cleavage cocktail was added: TFA : TIS : $\mathrm{H}_{2} \mathrm{O}(10 \mathrm{~mL}, 95: 2.5: 2.5)$. The reaction mixture was stirred for $2 \mathrm{~h}$ at room temperature and the resin was then filtered and washed with TFA. The solution was concentrated under reduced pressure and the crude product was precipitated in ice cold $\mathrm{Et}_{2} \mathrm{O}$. The final purification was performed by reversed phase flash chromatography (SNAP Ultra C18 $12 \mathrm{~g}, \mathrm{H}_{2} \mathrm{O} / \mathrm{MeCN}$ from $0 \%$ to $60 \% \mathrm{MeCN}$ ). The product was obtained as white crystal $(53.5 \mathrm{mg}, 0.13 \mathrm{mmol}, 65 \%$, purity $>97 \%)$.

${ }^{1} \mathrm{H}$ NMR $\left(400 \mathrm{MHz}, \mathrm{D}_{2} \mathrm{O}\right) \delta: 4.52\left(\mathrm{q}, J=3 \mathrm{~Hz}, 1 \mathrm{H}\right.$, Cys $\left.\mathrm{CHCH}_{2}\right)$, $3.92\left(\mathrm{~s}, 2 \mathrm{H}, \mathrm{Gly} \mathrm{CH}_{2} \mathrm{COOH}\right), 3.81$ (t, $J=7 \mathrm{~Hz}, 1 \mathrm{H}$, Glu ${\mathrm{C} H \mathrm{NH}_{2}}_{2}$ ), $3.67\left(\mathrm{t}, J=6 \mathrm{~Hz}, 2 \mathrm{H}, \mathrm{CH}_{2} \mathrm{OH}\right), 3.04-2.83\left(\mathrm{~m}, 2 \mathrm{H}, \mathrm{Cys} \mathrm{CHCH}_{2} \mathrm{~S}\right)$, $2.81\left(\mathrm{~s}, 4 \mathrm{H}, \mathrm{SCH}_{2} \mathrm{CH}_{2} \mathrm{~S}\right), 2.76\left(\mathrm{t}, J=6 \mathrm{~Hz}, 2 \mathrm{H}, \mathrm{CH}_{2} \mathrm{CH}_{2} \mathrm{OH}\right), 2.50$ (q, $J=5 \mathrm{~Hz}, 2 \mathrm{H}$, Glu $\mathrm{CH}_{2} \mathrm{CH}_{2} \mathrm{CONH}$ ), $2.11(\mathrm{t}, J=7 \mathrm{~Hz}, 2 \mathrm{H}$, Glu $\left.\mathrm{CH}_{2} \mathrm{CH}_{2} \mathrm{CONH}\right)$ ppm.

${ }^{13} \mathrm{C}$ NMR $\left\{{ }^{1} \mathrm{H}\right\}\left(100 \mathrm{MHz}, \mathrm{D}_{2} \mathrm{O}\right) \delta: 174.7$ (CO), $173.14(\mathrm{CO})$, 173.09 (CO), $172.7(\mathrm{CO}), 60.3\left(\mathrm{CH}_{2} \mathrm{OH}\right), 53.4\left(\mathrm{Cys} \mathrm{CHCH}_{2}\right), 53.1$ (Glu $\mathrm{CHNH}_{2}$ ), $41.3\left(\mathrm{Gly} \mathrm{CH}_{2} \mathrm{COOH}\right.$ ), $33.3\left(\mathrm{CH}_{2} \mathrm{CH}_{2} \mathrm{OH}\right), 32.7$ (Cys $\begin{array}{lllllll}\left.\mathrm{CHCH}_{2} \mathrm{~S}\right), & 31.6 & \& & 31.1 & \left(\mathrm{SCH}_{2} \mathrm{CH}_{2} \mathrm{~S}\right), & 25.8 & \text { (Glu }\end{array}$ $\mathrm{CH}_{2} \mathrm{CH}_{2} \mathrm{CONH}$ ) ppm.

HRMS (ESI/Q-TOF) $m / z[M+\mathrm{H}]^{+}$calcd for $\mathrm{C}_{14} \mathrm{H}_{26} \mathrm{~N}_{3} \mathrm{O}_{7} \mathrm{~S}_{2}$ 412.1206, found: 412.1207 .

FTIR (neat): 3335, 2532, 1644, 1516, 1414, 1229, 1022, $678 \mathrm{~cm}^{-1}$

\section{Glutathione-ethylthioethyl-glutathione, GSH-ETE-GSH 7}

To a solution of GSH (1.310 g, $4.26 \mathrm{mmol}, 1$ equiv.) in sat. aq. $\mathrm{NaHCO}_{3}(10 \mathrm{~mL})$ was added dropwise a solution of sulfur mustard ( $0.323 \mathrm{~g}, 2.03 \mathrm{mmol}, 0.5$ equiv.) in $\mathrm{MeCN}(10 \mathrm{~mL})$. The $\mathrm{pH}$ of the solution was kept at 8-9 by the addition of aq. $\mathrm{NaOH}$ $(0.1 \mathrm{M})$. The mixture was stirred at room temperature until complete consumption of sulfur mustard (118 h, monitored by GC-MS) was observed. The mixture was washed with DCM $(3 \times$ $15 \mathrm{~mL}$ ) and the aqueous layer was concentrated under reduced pressure. The crude product was purified by reversed phase flash chromatography (Biotage, SNAP Ultra C18 $60 \mathrm{~g}, 25 \%$ to $95 \% \mathrm{H}_{2} \mathrm{O}$ in $\left.\mathrm{MeCN}\right)$. The solvent was evaporated and the product purified again by normal phase flash chromatography (SNAP Ultra $50 \mathrm{~g}$, DCM/MeOH from $5 \%$ to $100 \% \mathrm{MeOH}$ ). The solvent was evaporated and the residue dried under reduced pressure. The product was obtained as a colorless solid $(922 \mathrm{mg}$, $1.32 \mathrm{mmol}, 65 \%$, purity $>85 \%$ ).

${ }^{1} \mathrm{H}$ NMR $\left(400 \mathrm{MHz}, \mathrm{D}_{2} \mathrm{O}\right) \delta: 4.62-4.59(\mathrm{~m}, 2 \mathrm{H}, 2 \times$ Cys $\left.\mathrm{CHCH}_{2}\right), 3.82\left(\mathrm{~d}, J=4 \mathrm{~Hz}, 4 \mathrm{H}, 2 \times \mathrm{Gly} \mathrm{CH}_{2} \mathrm{COOH}\right), 3.81-3.74(\mathrm{~m}$, $2 \mathrm{H}, 2 \times$ Glu $\mathrm{CHNH}_{2}$ ), 3.12 (dd, $J=6 \mathrm{~Hz}, J=14 \mathrm{~Hz}, 2 \mathrm{H}$, Cys $\mathrm{CHCH}_{2} \mathrm{~S}$ ), $2.91\left(\mathrm{dd}, J=8 \mathrm{~Hz}, J=14 \mathrm{~Hz}, 2 \mathrm{H}\right.$, Cys $\mathrm{CHCH}_{2} \mathrm{~S}$ ), 2.85 (s, $\left.8 \mathrm{H}, 2 \times \mathrm{SCH}_{2} \mathrm{CH}_{2} \mathrm{~S}\right), 2.61-2.47\left(\mathrm{~m}, 4 \mathrm{H}, 2 \times{\mathrm{Glu} \mathrm{CH}_{2} \mathrm{CH}_{2}-}^{-}\right.$ $\mathrm{CONH}$ ), 2.17 (q, $\left.J=8 \mathrm{~Hz}, 4 \mathrm{H}, 2 \times \mathrm{Glu} \mathrm{CH}_{2} \mathrm{CH}_{2} \mathrm{CONH}\right) \mathrm{ppm}$. 
${ }^{13} \mathrm{C}$ NMR $\left\{{ }^{1} \mathrm{H}\right\}\left(100 \mathrm{MHz}, \mathrm{D}_{2} \mathrm{O}\right) \delta: 175.8(2 \times C \mathrm{O}), 174.9(2 \times$ CO), $173.9(2 \times \mathrm{CO}), 172.0(2 \times \mathrm{CO}), 54.1\left(2 \times \mathrm{Cys}_{\mathrm{CHCH}}\right), 53.1$ $\left(2 \times\right.$ Glu $\left.\mathrm{CHNH}_{2}\right), 43.1\left(2 \times\right.$ Gly $\left.\mathrm{CH}_{2} \mathrm{COOH}\right), 32.9(2 \times$ Cys $\left.\mathrm{CHCH}_{2} \mathrm{~S}\right), 31.5 \& 31.4\left(2 \times \mathrm{SCH}_{2} \mathrm{CH}_{2} \mathrm{~S}\right), 31.0\left(2 \times \mathrm{Glu} \mathrm{CH}_{2} \mathrm{CH}_{2}-\right.$ $\mathrm{CONH}), 26.2\left(2 \times\right.$ Glu $\left.\mathrm{CH}_{2} \mathrm{CH}_{2} \mathrm{CONH}\right) \mathrm{ppm}$.

HRMS (ESI/Q-TOF) $m / z[\mathrm{M}+\mathrm{H}]^{+}$calcd for $\mathrm{C}_{24} \mathrm{H}_{41} \mathrm{~N}_{6} \mathrm{O}_{12} \mathrm{~S}_{3}$ 701.1945, found: 701.1964 .

FTIR (neat) 1589, 1519, 1390, 1309, 1026, 534, 522.

\section{$N, S$-Bis(tert-butoxycarbonyl)glutathione, $N, S$-Boc-GSH 11}

GSH (1.23 g, 4.0 mmol, 1 equiv.) and $\mathrm{NaHCO}_{3}(1.48 \mathrm{~g}$, $17.6 \mathrm{mmol}, 4.4$ equiv.) were dissolved in $\mathrm{THF} / \mathrm{H}_{2} \mathrm{O}(28 \mathrm{~mL}, 2: 5)$. $\mathrm{Boc}_{2} \mathrm{O}$ (3.84 g, $17.6 \mathrm{mmol}, 4.4$ equiv.) was added to the solution. The reaction mixture was stirred for $24 \mathrm{~h}$ at room temperature. It was then acidified to $\mathrm{pH} 2$ with aq. $\mathrm{HCl} 37 \%$ and extracted with EtOAc $(3 \times 20 \mathrm{~mL})$. The combined organic layers were dried over $\mathrm{MgSO}_{4}$ and the solvent was removed under reduced pressure after filtration. The crude product was obtained as a white solid (2.93 g, purity 50\%). $2.02 \mathrm{~g}$ of the crude was purified by flash chromatography (SNAP Ultra $100 \mathrm{~g}, \mathrm{DCM} /$ $\mathrm{MeOH}$ from $13 \%$ to $100 \% \mathrm{MeOH})$. After evaporation of the solvent the product was obtained as a white solid (949 mg, $1.87 \mathrm{mmol}, 47 \%$, purity $>85 \%$ ). The product contained different stereoisomers and also mono-protected GSH as impurities.

${ }^{1} \mathrm{H}$ NMR (400 MHz, DMSO-d 6 ) $\delta: 12.62$ (br. s., 2H, Glu \& Gly $\mathrm{COOH}), 8.19(\mathrm{~d}, J=9 \mathrm{~Hz}, 1 \mathrm{H}$, Glu NH), $8.08(\mathrm{t}, J=6 \mathrm{~Hz}, 1 \mathrm{H}$, Gly $\mathrm{NH}), 6.81$ (d, $J=8 \mathrm{~Hz}, 1 \mathrm{H}$, Cys $\mathrm{N} H), 4.48-4.43(\mathrm{~m}, 1 \mathrm{H}$, Cys $\mathrm{CHCH}_{2}$ ), 3.86-3.81 (m, 1H, Glu $\mathrm{CHNH}_{2}$ ), 3.64-3.62 (m, 2H, Gly $\mathrm{CH}_{2} \mathrm{COOH}$ ), 3.21 (dd, $J=5 \mathrm{~Hz}, J=14 \mathrm{~Hz}, 1 \mathrm{H}, \mathrm{Cys} \mathrm{CHCH}_{2} \mathrm{~S}$ ), 2.92 (dd, $J=9 \mathrm{~Hz}, J=13 \mathrm{~Hz}, 1 \mathrm{H}$, Cys $\mathrm{CHCH}_{2} \mathrm{~S}$ ), 2.18 (t, $J=7 \mathrm{~Hz}, 2 \mathrm{H}$, Glu $\left.\mathrm{CH}_{2} \mathrm{CH}_{2} \mathrm{CONH}\right)$, 1.92-1.87 (m, $1 \mathrm{H}$, Glu $\left.\mathrm{CH}_{2} \mathrm{CH}_{2} \mathrm{CONH}\right)$, 1.83-1.77 (m, 1H, Glu $\left.\mathrm{CH}_{2} \mathrm{CH}_{2} \mathrm{CONH}\right), 1.44\left(\mathrm{~s}, 9, \mathrm{C}\left(\mathrm{CH}_{3}\right)_{3}\right), 1.37$ (s, 9H, C( $\left.\left.\left.\mathrm{CH}_{3}\right)_{3}\right)\right)$ ppm.

${ }^{13} \mathrm{C}$ NMR $\left\{{ }^{1} \mathrm{H}\right\}\left(100 \mathrm{MHz}, \mathrm{DMSO}-\mathrm{d}_{6}\right) \delta: 174.6(C \mathrm{O}), 172.3(\mathrm{CO})$, $171.5(\mathrm{CO}), 170.1(\mathrm{CO}), 168.6(\mathrm{CO}), 155.8\left(\mathrm{NHCOOC}\left(\mathrm{CH}_{3}\right)_{3}\right), 85.3$

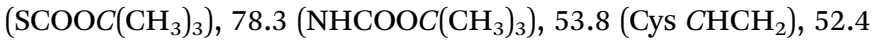
(Glu $\mathrm{CHNH}_{2}$ ), 42.3 (Gly $\mathrm{CH}_{2} \mathrm{COOH}$ ), 33.0 (Cys $\left.\mathrm{CHCH}_{2} \mathrm{~S}\right), 28.7$ (Glu $\mathrm{CH}_{2} \mathrm{CH}_{2} \mathrm{CONH}$ ), 28.2 (Glu $\mathrm{CH}_{2} \mathrm{CH}_{2} \mathrm{CONH}$ ), 27.7 $\left(\mathrm{NHCOOC}\left(\mathrm{CH}_{3}\right)_{3}\right), 21.6\left(\mathrm{SCOOC}\left(\mathrm{CH}_{3}\right)_{3}\right) \mathrm{ppm}$.

HRMS (ESI/Q-TOF) $m / z[\mathrm{M}+\mathrm{H}]^{+}$calcd for $\mathrm{C}_{20} \mathrm{H}_{34} \mathrm{~N}_{3} \mathrm{O}_{10} \mathrm{~S}$ 508.1959, found: 508.1951 .

FTIR (neat): 2446, 2410, 2402, 2328, 2314, 2304, 2277, 2265, 1711, 1602, 1524, 1516, 1448, 1414, 1318, 1223, 1179, 1124, $1031,1006,943,907,875,845,759,735,662,647,620 \mathrm{~cm}^{-1}$.

Mp $93{ }^{\circ} \mathrm{C}$.

\section{O-Bis(2-(2-(hydroxy)ethylthio)ethyl)-N,S-bis(tert- butoxycarbonyl)glutathione, bis-O-HETE- $N, S$-Boc-GSH 12}

To a solution of 11 (500 mg, $0.985 \mathrm{mmol}, 1$ equiv.) and thiodiglycol (2.65 mL, $25.61 \mathrm{mmol}, 26$ equiv.) in anhydrous EtOAc (7.5 mL) under inert gas atmosphere were added HOBt (332 mg, $2.17 \mathrm{mmol}, 2.2$ equiv.), DMAP (144 mg, $1.18 \mathrm{mmol}, 1.2$ equiv.) and EDC (0.42 mL, $2.36 \mathrm{mmol}, 2.4$ equiv.) at $0{ }^{\circ} \mathrm{C}$. The reaction mixture was stirred for $30 \mathrm{~min}$ at $0{ }^{\circ} \mathrm{C}$ and then for $22 \mathrm{~h}$ at room temperature. It was then washed with aq. $\mathrm{HCl}(2 \%, 8 \mathrm{~mL})$, aq. $\mathrm{NaHCO}_{3}(2 \%, 8 \mathrm{~mL})$ and $\mathrm{H}_{2} \mathrm{O}(8 \mathrm{~mL})$. The organic layer was dried over $\mathrm{MgSO}_{4}$ and the solvent was removed under reduced pressure. The product was obtained as a colorless viscous oil (445 mg [estimated dry mass; product still contained EtOAc (27\%), which could not be removed: wet mass $622 \mathrm{mg}$ ], $0.62 \mathrm{mmol}, 63 \%$, purity $>68 \%$ ).

${ }^{1} \mathrm{H}$ NMR $\left(400 \mathrm{MHz}, \mathrm{CDCl}_{3}\right) \delta: 6.99(\mathrm{~d}, J=7 \mathrm{~Hz}, 1 \mathrm{H}$, Cys $\mathrm{NH})$, 5.40 (d, $J=7 \mathrm{~Hz}, 1 \mathrm{H}$, Glu NH), 4.69-4.64 (m, 1H, Cys $\mathrm{CHCH}_{2}$ ), 4.39-4.27 (m, 5H, SCH $\mathrm{CH}_{2} \mathrm{OOC}-\mathrm{Glu} \& \mathrm{Glu} \mathrm{CHNH}$ \& Gly $\mathrm{CH}_{2} \mathrm{COO}$ ), 4.12 (dd, $J=6 \mathrm{~Hz}, J=18 \mathrm{~Hz}, 1 \mathrm{H}, \mathrm{SCH}_{2} \mathrm{CH}_{2}$ OOC-Gly), 3.96 (dd, $J=5 \mathrm{~Hz}, J=18 \mathrm{~Hz}, 1 \mathrm{H}, \mathrm{SCH}_{2} \mathrm{CH}_{2} \mathrm{OOC}-\mathrm{Gly}$ ), 3.78-3.76 (m, $\left.4 \mathrm{H}, 2 \times \mathrm{CH}_{2} \mathrm{OH}\right), 3.28(\mathrm{dd}, J=5 \mathrm{~Hz}, J=15 \mathrm{~Hz}, 1 \mathrm{H}$, Cys $\mathrm{CHCH}_{2} \mathrm{~S}$ ), 3.17 (dd, $J=8 \mathrm{~Hz}, J=15 \mathrm{~Hz}, 1 \mathrm{H}, \mathrm{Cys} \mathrm{CHCH}_{2} \mathrm{~S}$ ), 2.99 (br. s, $1 \mathrm{H}, \mathrm{OH}), 2.84-2.76\left(\mathrm{~m}, 9 \mathrm{H}, 2 \times \mathrm{HOCH}_{2} \mathrm{CH}_{2} \mathrm{SCH}_{2} \mathrm{CH}_{2} \mathrm{OOC}\right.$ \& $\mathrm{OH}), 2.43-2.31\left(\mathrm{~m}, 2 \mathrm{H}\right.$, Glu $\left.\mathrm{CH}_{2} \mathrm{CH}_{2} \mathrm{CONH}\right), 2.20-2.15(\mathrm{~m}, 1 \mathrm{H}$, Glu $\mathrm{CH}_{2} \mathrm{CH}_{2} \mathrm{CONH}$ ), 2.09-2.04 (m, $1 \mathrm{H}$, Glu $\left.\mathrm{CH}_{2} \mathrm{CH}_{2} \mathrm{CONH}\right), 1.50$ $\left(\mathrm{s}, 9 \mathrm{H}, \mathrm{C}\left(\mathrm{CH}_{3}\right)_{3}\right), 1.44\left(\mathrm{~s}, 9 \mathrm{H}, \mathrm{C}\left(\mathrm{CH}_{3}\right)_{3}\right) \mathrm{ppm}$.

${ }^{13} \mathrm{C}$ NMR $\left\{{ }^{1} \mathrm{H}\right\}\left(100 \mathrm{MHz}, \mathrm{CDCl}_{3}\right) \delta: 172.8(\mathrm{CO}), 172.3(\mathrm{CO})$, $170.5(\mathrm{CO}), 170.0(\mathrm{CO}), 169.4(\mathrm{CO}), 85.9\left(\mathrm{SCOOC}\left(\mathrm{CH}_{3}\right)_{3}\right), 77.2$ $\left(\mathrm{NHCOOC}\left(\mathrm{CH}_{3}\right)_{3}\right), 64.7\left(\mathrm{SCH}_{2} \mathrm{CH}_{2} \mathrm{OOC}\right), 64.6\left(\mathrm{SCH}_{2} \mathrm{CH}_{2} \mathrm{OOC}\right)$, $61.0\left(\mathrm{CH}_{2} \mathrm{OH}\right), 61.0\left(\mathrm{CH}_{2} \mathrm{OH}\right), 53.8\left(\mathrm{Cys} \mathrm{CHCH}_{2}\right), 52.8$ (Glu $\mathrm{CHNH}$ ), 41.5 (Gly $\left.\mathrm{CH}_{2} \mathrm{COO}\right), 35.4\left(\mathrm{CH}_{2} \mathrm{CH}_{2} \mathrm{OH}\right), 35.4\left(\mathrm{CH}_{2} \mathrm{CH}_{2}-\right.$ $\mathrm{OH}$ ), 32.0 (Cys $\left.\mathrm{CHCH}_{2} \mathrm{~S}\right), 30.5\left(\mathrm{SCH}_{2} \mathrm{CH}_{2} \mathrm{OOC}\right), 30.3\left(\mathrm{SCH}_{2} \mathrm{CH}_{2}-\right.$ OOC), $28.3\left(\mathrm{C}\left(\mathrm{CH}_{3}\right)_{3}\right), 28.2\left(\mathrm{C}\left(\mathrm{CH}_{3}\right)_{3}\right) \mathrm{ppm}$.

HRMS (ESI/Q-TOF) $m / z[\mathrm{M}+\mathrm{H}]^{+}$calcd for $\mathrm{C}_{28} \mathrm{H}_{50} \mathrm{~N}_{3} \mathrm{O}_{12} \mathrm{~S}_{3}$ 716.2551, found: 716.2557 .

FTIR (neat): 3099, 3001, 2987, 2955, 2939, 2882, 2224, 2196, $21886,2157,2134,2118,1960,1937,1741,1697,1655,1507$, 1476, 1456, 1394, 1369, 1349, 1285, 1210, 1162, 1123, 1058, 1032, 1006, 963, 895, 855, 834, 651, $568 \mathrm{~cm}^{-1}$.

\section{O-Bis(2-(2-(hydroxy)ethylthio)ethyl)glutathione, bis-O-HETE- GSH 8}

A solution of TFA : TFE : $\mathrm{H}_{2} \mathrm{O}(8.65 \mathrm{~mL}, 80: 10: 10)$ was added dropwise to 12 (376 mg, $0.525 \mathrm{mmol}, 1$ equiv.) at $0{ }^{\circ} \mathrm{C}$. After addition, the mixture was allowed to warm to room temperature and was stirred for $2 \mathrm{~h}$. The solvent was evaporated under reduced pressure. The crude product was purified by flash chromatography (SNAP Ultra $50 \mathrm{~g}, \mathrm{DCM} / \mathrm{MeOH}$ from $2 \%$ to $100 \% \mathrm{MeOH})$ to afford a colorless viscous oil $(328 \mathrm{mg}$, $0.636 \mathrm{mmol}, 91 \%$, purity $>75 \%)$.

${ }^{1} \mathrm{H}$ NMR (400 MHz, $\left.\mathrm{D}_{2} \mathrm{O}\right) \delta: 4.57\left(\mathrm{t}, J=7 \mathrm{~Hz}, 1 \mathrm{H}, \mathrm{Cys} \mathrm{CHCH}_{2}\right)$, $4.46\left(\mathrm{t}, J=6 \mathrm{~Hz}, 2 \mathrm{H}, \mathrm{SCH}_{2} \mathrm{CH}_{2} \mathrm{OOC}-\mathrm{Glu}\right), 4.36(\mathrm{t}, J=6 \mathrm{~Hz}, 2 \mathrm{H}$, Gly $\left.\mathrm{CH}_{2} \mathrm{COO}\right), 4.23$ (t, $J=7 \mathrm{~Hz}, 1 \mathrm{H}$, Glu $\left.\mathrm{CHNH}\right), 4.08$ (d, $J=5 \mathrm{~Hz}$, $2 \mathrm{H}, \mathrm{SCH}_{2} \mathrm{CH}_{2} \mathrm{OOC}-\mathrm{Gly}$ ), 3.77 (td, $J=2 \mathrm{~Hz}, J=8 \mathrm{~Hz}, 4 \mathrm{H}, 2 \times$ $\left.\mathrm{CH}_{2} \mathrm{OH}\right), 2.95$ (q, $\left.J=7 \mathrm{~Hz}, 4 \mathrm{H}, 2 \times \mathrm{SCH}_{2} \mathrm{CH}_{2} \mathrm{OOC}\right), 2.89(\mathrm{t}, J=$ $7 \mathrm{~Hz}, 2 \mathrm{H}$, Cys $\left.\mathrm{CHCH}_{2} \mathrm{~S}\right), 2.78(\mathrm{td}, J=2 \mathrm{~Hz}, J=8 \mathrm{~Hz}, 4 \mathrm{H}, 2 \times$ $\mathrm{SCH}_{2} \mathrm{CH}_{2} \mathrm{OH}$ ), 2.72-2.58 (m, 2H, Glu $\mathrm{CH}_{2} \mathrm{CH}_{2} \mathrm{CONH}$ ), 2.35-2.23 (m, 2H, Glu $\mathrm{CH}_{2} \mathrm{CH}_{2} \mathrm{CONH}$ ) ppm.

${ }^{13} \mathrm{C}$ NMR $\left\{{ }^{1} \mathrm{H}\right\}\left(100 \mathrm{MHz}, \mathrm{D}_{2} \mathrm{O}\right) \delta: 174.1$ (CO), 172.7 (CO), 171.0 (CO), 169.5 (CO), $65.3\left(\mathrm{SCH}_{2} \mathrm{CH}_{2} \mathrm{OOC}\right), 64.7\left(\mathrm{SCH}_{2} \mathrm{CH}_{2}-\right.$ OOC), $60.3\left(2 \times \mathrm{CH}_{2} \mathrm{OH}\right), 55.5\left(\mathrm{Cys} \mathrm{CHCH}_{2}\right), 52.1\left(\mathrm{Glu} C \mathrm{HNH}_{2}\right)$, 41.3 (Gly $\mathrm{CH}_{2} \mathrm{COO}$ ), $33.6\left(\mathrm{SCH}_{2} \mathrm{CH}_{2} \mathrm{OH}\right), 33.5\left(\mathrm{SCH}_{2} \mathrm{CH}_{2} \mathrm{OH}\right)$, 30.6 (Glu $\left.\mathrm{CH}_{2} \mathrm{CH}_{2} \mathrm{CONH}\right), 29.7\left(\mathrm{SCH}_{2} \mathrm{CH}_{2} \mathrm{OOC}\right), 29.6\left(\mathrm{SCH}_{2}\right.$ $\mathrm{CH}_{2} \mathrm{OOC}$ ), 25.4 (Glu $\mathrm{CH}_{2} \mathrm{CH}_{2} \mathrm{CONH}$ ), $25.3\left(\mathrm{Cys} \mathrm{CHCH}_{2} \mathrm{~S}\right.$ ) ppm.

HRMS (ESI/Q-TOF) $\mathrm{m} / z[\mathrm{M}+\mathrm{H}]^{+}$calcd for $\mathrm{C}_{18} \mathrm{H}_{34} \mathrm{~N}_{3} \mathrm{O}_{8} \mathrm{~S}_{3}$ 516.1508, found: 516.1503 . 
FTIR (neat): 2264, 2248, 2237, 2228, 2044, 1744, 1666, 1527, 1462, 1423, 1360, 1196, 1131, 1065, 722, $630 \mathrm{~cm}^{-1}$.

$O$-(2-(2-(tert-Butoxy)ethylthio)ethyl)- $N$-(tert-butoxycarbonyl)-Lglutamic acid 5-((9H-fluoren-9-yl)methyl) ester, BocGlu(OFm)-O-ETEOtBu 14

A solution of DIPEA ( $421 \mu \mathrm{L}, 2.4 \mathrm{mmol}, 1$ equiv.) in degassed DCM (15 mL) was added to Boc-Glu(OFm)-OH (1000 g, $2.4 \mathrm{mmol}, 1$ equiv.). The solution was stirred $5 \mathrm{~min}$ and a solution of HCTU (1458 mg, $3.5 \mathrm{mmol}, 1.5$ equiv.) and DIPEA (421 $\mu \mathrm{L}, 2.4 \mathrm{mmol}, 1$ equiv.) in degassed DCM/DFM (40 mL, $1: 1$ ) was added dropwise at $0{ }^{\circ} \mathrm{C}$. The solution was stirred $10 \mathrm{~min}$ at $0{ }^{\circ} \mathrm{C}$ and a solution of $\mathbf{1}$ ( $838 \mathrm{mg}, 4.7 \mathrm{mmol}, 2$ equiv.) in DCM ( 5 $\mathrm{mL}$ ) was then added. The reaction mixture was stirred for $1 \mathrm{~h}$ at $0{ }^{\circ} \mathrm{C}$ and $24 \mathrm{~h}$ at room temperature. The solution was washed with aq $\mathrm{HCl}(2 \%, 20 \mathrm{~mL})$, aq. $\mathrm{NaHCO}_{3}(2 \%, 20 \mathrm{~mL})$ and $\mathrm{H}_{2} \mathrm{O}(20$ $\mathrm{mL}$ ). The organic fraction was dried over $\mathrm{Na}_{2} \mathrm{SO}_{4}$, the solvent was concentrated under reduced pressure and the crude product was purified by normal phase flash chromatography (SNAP Ultra $25 \mathrm{~g}$, hexane/EtOAc from $0 \%$ to $20 \%$ EtOAc). The product was obtained as a yellowish oil $(1.5 \mathrm{~g}, 110 \%$, purity $>$ $66 \%)$.

${ }^{1} \mathrm{H}$ NMR $\left(400 \mathrm{MHz}, \mathrm{CDCl}_{3}\right) \delta: 7.77(\mathrm{~d}, J=8 \mathrm{~Hz}, 2 \mathrm{H}, \mathrm{Fm}), 7.59$ $(\mathrm{d}, J=7 \mathrm{~Hz}, 2 \mathrm{H}, \mathrm{Fm}), 7.42(\mathrm{t}, J=7 \mathrm{~Hz}, 2 \mathrm{H}, \mathrm{Fm}), 7.31(\mathrm{t}, J=7 \mathrm{~Hz}$, $2 \mathrm{H}, \mathrm{Fm}), 5.15$ (d, $J=8 \mathrm{~Hz}, 1 \mathrm{H}, \mathrm{NH}), 4.39$ (d, $J=7 \mathrm{~Hz}, 2 \mathrm{H}, \mathrm{Fm}$ $\left.\mathrm{CH}_{2}\right), 4.32(\mathrm{t}, J=7 \mathrm{~Hz}, 2 \mathrm{H}, \mathrm{Fm} \mathrm{CH} \& \mathrm{C}(\mathrm{O}) \mathrm{CH}), 4.21(\mathrm{t}, J=7 \mathrm{~Hz}$, $\left.2 \mathrm{H}, \mathrm{COOCH}_{2} \mathrm{CH}_{2} \mathrm{~S}\right), 3.76\left(\mathrm{t}, J=6 \mathrm{~Hz}, 2 \mathrm{H}, \mathrm{CH}_{2} \mathrm{O} t \mathrm{Bu}\right), 3.53(\mathrm{t}, J=$ $7 \mathrm{~Hz}, 2 \mathrm{H}), 2.83\left(\mathrm{t}, J=7 \mathrm{~Hz}, 2 \mathrm{H}, \mathrm{COOCH}_{2} \mathrm{CH}_{2} \mathrm{~S}\right), 2.67$ (t, $J=7 \mathrm{~Hz}$, $\left.2 \mathrm{H}, \mathrm{SCH}_{2} \mathrm{CH}_{2} \mathrm{OtBu}\right), 2.52-2.48\left(\mathrm{~m}, 2 \mathrm{H}, \mathrm{CH}_{2} \mathrm{CH}_{2} \mathrm{CH}\right), 2.23-1.92$ $\left(\mathrm{m}, 2 \mathrm{H}, \mathrm{CH}_{2} \mathrm{CH}_{2} \mathrm{CH}\right), 1.62\left(\mathrm{~s}, 9 \mathrm{H}, \mathrm{C}\left(\mathrm{CH}_{3}\right)_{3}\right), 1.17(\mathrm{~s}, 9 \mathrm{H}$, $\left.\mathrm{C}\left(\mathrm{CH}_{3}\right)_{3}\right)$ ppm.

${ }^{13} \mathrm{C} \mathrm{NMR}\left\{{ }^{1} \mathrm{H}\right\}\left(100 \mathrm{MHz}, \mathrm{CDCl}_{3}\right) \delta: 172.7$ (CO), $172.0(\mathrm{CO})$, 156.6 (COOtBu), $143.8(\mathrm{Fm}), 141.3(\mathrm{Fm}), 127.8(\mathrm{Fm}), 127.15$

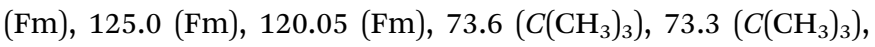
$66.4\left(\mathrm{Fm} \mathrm{CH} \mathrm{CH}_{2}\right), 64.5\left(\mathrm{CH}_{2} \mathrm{COO} t \mathrm{Bu}\right), 62.1\left(\mathrm{COOCH}_{2} \mathrm{CH}_{2} \mathrm{~S}\right), 52.9$ $(\mathrm{NHCH}), 46.8(\mathrm{Fm} \mathrm{CH}), 36.5\left(\mathrm{SCH}_{2} \mathrm{CH}_{2} \mathrm{OtBu}\right), 32.9\left(\mathrm{COOCH}_{2}-\right.$ $\left.\mathrm{CH}_{2} \mathrm{~S}\right), \quad 30.3 \quad\left(\mathrm{CH}_{2} \mathrm{COOFm}\right), \quad 27.5 \quad\left(\mathrm{CH}_{2} \mathrm{CH}_{2} \mathrm{COOFm}\right), \quad 27.5$ $\left(\mathrm{CH}_{3}\right) \mathrm{ppm}$.

HRMS (ESI/Q-TOF) $m / z[\mathrm{M}+\mathrm{H}]^{+}$calcd for $\mathrm{C}_{32} \mathrm{H}_{44} \mathrm{NO}_{7} \mathrm{~S}$ 586.2833 , found: 586.2824 .

FTIR (neat): 3376, 2973, 2930, 1737, 1714, 1504, 1477, 1450, 1390, 1364, 1294, 1251, 1162, 1091, 1071, 1024, 989, 909, 883, $760,741,631,532 \mathrm{~cm}^{-1}$.

$O$-(2-(2-(tert-Butoxy)ethylthio)ethyl)- $N$-(tert-butoxycarbonyl)-Lglutamic acid, Boc-Glu(OH)-O-ETEOtBu 15

17 (200 mg, $0.3 \mathrm{mmol}, 1$ equiv.) was dissolved in $20 \%$ piperidine in DMF $(6 \mathrm{~mL})$ and the solution was stirred at room temperature for $24 \mathrm{~h}$. The reaction progress was monitored by direct injection (negative ESI mode) into the Dalton mass detector. The solvent was removed under reduced pressure and the crude product was purified by normal phase flash chromatography (SNAP Ultra $10 \mathrm{~g}$, hexane/EtOAc from $0 \%$ to 80\% EtOAc) and dried by lyophilisation. The product was obtained as a colorless oil (90 mg, $0.2 \mathrm{mmol}, 65 \%$, purity > 97\%).
${ }^{1} \mathrm{H}$ NMR (400 MHz, $\left.\mathrm{CD}_{3} \mathrm{CN}\right) \delta: 7.49(\mathrm{~d}, J=7.5 \mathrm{~Hz}, 1 \mathrm{H}, \mathrm{NH})$, $4.27\left(\mathrm{~m}, 2 \mathrm{H}, \mathrm{CHCOOCH}_{2}\right), 4.17(\mathrm{~m}, 1 \mathrm{H}, \mathrm{NHCH}), 3.55(\mathrm{t}, J=$ $\left.6.3 \mathrm{~Hz}, 2 \mathrm{H}, \mathrm{CH}_{2} \mathrm{OtBu}\right), 2.82\left(\mathrm{t}, J=6.6 \mathrm{~Hz}, 2 \mathrm{H}, \mathrm{COOCH}_{2} \mathrm{CH}_{2} \mathrm{~S}\right.$ ), $2.67\left(\mathrm{t}, J=6.5 \mathrm{~Hz}, 2 \mathrm{H}, \mathrm{CH}_{2} \mathrm{CH}_{2} \mathrm{O} t \mathrm{Bu}\right), 2.41(\mathrm{t}, J=7.2 \mathrm{~Hz}, 2 \mathrm{H}$, $\mathrm{CH}_{2} \mathrm{CH}_{2} \mathrm{COOH}$ ), 2.09-1.86 (m, 2H, $\left.\mathrm{CH}_{2} \mathrm{CH}_{2} \mathrm{COOH}\right), 1.43$ (s, 9H, $\left.\mathrm{C}\left(\mathrm{CH}_{3}\right)_{3}\right), 1.19\left(\mathrm{~s}, 9 \mathrm{H}, \mathrm{C}\left(\mathrm{CH}_{3}\right)_{3}\right) \mathrm{ppm}$.

${ }^{13} \mathrm{C} \mathrm{NMR}\left\{{ }^{1} \mathrm{H}\right\}\left(100 \mathrm{MHz}, \mathrm{CD}_{3} \mathrm{CN}\right) \delta: 174.2(\mathrm{CO}), 172.7(\mathrm{CO})$, $156.2(\mathrm{COO} t \mathrm{Bu}), 79.6\left(C\left(\mathrm{CH}_{3}\right)_{3}\right), 73.3\left(C\left(\mathrm{CH}_{3}\right)_{3}\right), 64.8\left(\mathrm{CH}_{2}{ }^{-}\right.$ $\mathrm{COO} t \mathrm{Bu}), 62.4\left(\mathrm{COOCH}_{2} \mathrm{CH}_{2} \mathrm{~S}\right), 53.6(\mathrm{NHCH}), 33.1,30.0\left(\mathrm{SCH}_{2}-\right.$ $\left.\mathrm{CH}_{2} \mathrm{O} t \mathrm{Bu}\right), 28.1\left(\mathrm{COOCH}_{2} \mathrm{CH}_{2} \mathrm{~S}\right), 27.4\left(\mathrm{CH}_{2} \mathrm{COOH}\right), 27.2\left(\mathrm{CH}_{3}\right)$, $27.1\left(\mathrm{CH}_{2} \mathrm{CH}_{2} \mathrm{COOH}\right)$ ppm.

HRMS (ESI/Q-TOF) $m / z[\mathrm{M}+\mathrm{H}]^{+}$calcd for $\mathrm{C}_{9} \mathrm{H}_{18} \mathrm{NO}_{4}$ 408.2051, found: 408.2045.

FTIR (neat): 3343, 2974, 2933, 1710, 1598, 1566, 1521, 1494, 1468, 1455, 1421, 1391, 1365, 1295, 1252, 1161, 1069, 1055, 1029, 1013, 992, 967, 913, 883, 858, 780, 756, 741, 727, 694, 677, $645,546 \mathrm{~cm}^{-1}$.

\section{O-(2-(2-(Hydroxy)ethylthio)ethyl)glutathione, O-HETE-GSH 9}

The synthesis of $O$-HETE-GSH 9 was performed by SPPS on a $0.2 \mathrm{mmol}$ scale. The preloaded H-Gly-2-ClTrt resin $(182 \mathrm{mg}$, loading $\left.1.1 \mathrm{mmol} \mathrm{g}^{-1}\right)$ was swelled with DMF $(4.5 \mathrm{~mL})$ over $2 \mathrm{~h}$ at room temperature. To the resin was then added FmocCys(Trt)-OH (498 mg, $0.8 \mathrm{mmol}, 4$ equiv.) in DMF (1.29 mL), DIC (128 $\mu \mathrm{L}, 0.8 \mathrm{mmol}, 4$ equiv.) in DMF (1.52 mL) and Oxyma pure (117 mg, $0.8 \mathrm{mmol}, 4$ equiv.) in DMF (1.65 mL). The reaction mixture was stirred for $3 \mathrm{~h}$ at room temperature. After DMF washes, a solution of piperidine $20 \%$ in DMF $(4.5 \mathrm{~mL}, 90$ equiv.) was added twice, for $5 \mathrm{~min}$ and $15 \mathrm{~min}$ agitation respectively.

After washing steps with DMF, Boc-Glu(OH)-OETEOtBu 18 (346 mg, $0.8 \mathrm{mmol}, 4$ equiv.) in DMF (1.42 mL), DIC $(128 \mu \mathrm{L}$, $0.8 \mathrm{mmol}, 4$ equiv.) in DMF $(1.52 \mathrm{~mL})$ and Oxyma pure $(117 \mathrm{mg}$, $0.8 \mathrm{mmol}, 4$ equiv.) in DMF $(1.65 \mathrm{~mL})$ were added to the resin. The reaction mixture was stirred for $3 \mathrm{~h}$ at room temperature, followed by a pre-cleavage wash of the resin with DCM $(4 \times 9$ $\mathrm{mL})$. An additional pre-cleavage wash with DCM $(4.5 \mathrm{~mL})$, $\mathrm{MeOH}(4.5 \mathrm{~mL})$ and DCM $(4.5 \mathrm{~mL})$ was performed by the instrument. The resin was transferred into a new flask and the following cleavage cocktail was added: TFA : TIS : $\mathrm{H}_{2} \mathrm{O}(10 \mathrm{~mL}$, $95: 2.5: 2.5)$. The reaction mixture was stirred for $2 \mathrm{~h}$ at room temperature and the resin was then filtered and washed with TFA. The solution was concentrated under reduced pressure and the crude product was precipitated in ice cold $\mathrm{Et}_{2} \mathrm{O}$. The final purification was performed by reversed phase flash chromatography (SNAP Ultra $\mathrm{C} 1812 \mathrm{~g}, \mathrm{H}_{2} \mathrm{O} / \mathrm{MeCN}$ from $0 \%$ to $60 \%$ $\mathrm{MeCN})$. The product was obtained as a white solid $(63.5 \mathrm{mg}$, $77 \%$, purity $>90 \%)$.

${ }^{1} \mathrm{H}$ NMR (400 MHz, $\left.\mathrm{D}_{2} \mathrm{O}\right) \delta: 4.48\left(\mathrm{~m}, 1 \mathrm{H}, \mathrm{NH}_{2} \mathrm{CH}\right), 4.36(\mathrm{t}, J=$ $\left.6.1 \mathrm{~Hz}, 2 \mathrm{H}, \mathrm{CHCOOCH}_{2}\right), 4.14(\mathrm{t}, J=6.1 \mathrm{~Hz}, 1 \mathrm{H}, \mathrm{NHCH}), 3.79(\mathrm{~s}$, $2 \mathrm{H}), 3.67\left(\mathrm{t}, J=6.2 \mathrm{~Hz}, 2 \mathrm{H}, \mathrm{CH}_{2} \mathrm{OH}\right), 2.88-2.83\left(\mathrm{~m}, 4 \mathrm{H}, \mathrm{S}\left(\mathrm{CH}_{2}\right)_{2}\right)$, $2.69(\mathrm{t}, J=6.2 \mathrm{~Hz}, 2 \mathrm{H}), 2.57\left(\mathrm{~m}, 2 \mathrm{H}, \mathrm{CHCH}_{2} \mathrm{CH}_{2}\right), 2.19(\mathrm{~m}, 2 \mathrm{H}$, $\left.\mathrm{CHCH}_{2}\right)$ ppm.

${ }^{13} \mathrm{C}$ NMR $\left\{{ }^{1} \mathrm{H}\right\}\left(100 \mathrm{MHz}, \mathrm{D}_{2} \mathrm{O}\right) \delta: 174.8(C \mathrm{O}), 174.2(\mathrm{CO})$, 171.8, 169.5, $65.3\left(\mathrm{CHCOOCH}_{2}\right), 60.3\left(\mathrm{CH}_{2} \mathrm{OH}\right), 55.5(C \mathrm{HN})$, 
52.1, 42.4, $33.5\left(\mathrm{CH}_{2} \mathrm{COOH}\right), \quad 30.7 \quad\left(\mathrm{SCH}_{2} \mathrm{CH}_{2} \mathrm{OH}\right), \quad 29.6$ $\left(\mathrm{COOCH}_{2} \mathrm{CH}_{2} \mathrm{~S}\right), 25.4\left(\mathrm{CH}_{2} \mathrm{CH}_{2} \mathrm{COOH}\right), 25.3 \mathrm{ppm}$.

HRMS (ESI/Q-TOF) $m / z[\mathrm{M}+\mathrm{H}]^{+}$calcd for $\mathrm{C}_{14} \mathrm{H}_{26} \mathrm{~N}_{3} \mathrm{O}_{7} \mathrm{~S}_{2}$ 412.1206, found: 412.1209.

IR (neat): 3730, 3627, 2362, 2338, $1017 \mathrm{~cm}^{-1}$.

\section{Conflicts of interest}

The authors declare no competing financial interests.

\section{Acknowledgements}

We thank the Federal Office for Civil Protection (FOCP) for the financial support of this work. Special thanks go to Dr Martin Schär for doing all the LC-HRMS measurements.

\section{References}

1 R. C. Malhorta, K. Ganesan, K. Surendran and R. V. Swamy, Def. Sci. J., 1999, 49, 97-166.

2 (a) L. Szinicz, Toxicology, 2005, 214, 167-181; (b) OPCW, Report of the OPCW fact-finding mission in Syria regarding alleged incidents in Marea, Syrian Arab Republic, August 2015, 2015, S/1320/2015; (c) OPCW, Report on the OPCW fact-finding mission in Syria regarding the incident of 16 September 2016 as reported in the note verbale of the Syrian Arab Republic number 113 dated 29 November 2016, 2017, S/ 1491/2017.

3 (a) Organisation for the Prohibition of Chemical Weapons, Convention on the Prohibition of the Development, Production, Stockpiling and Use of Chemical Weapons and on their Destruction, The Hague, 1994; (b) Organisation for the Prohibition of Chemical Weapons, http://www.opcw.org, 2018.

4 (a) C. M. Pechura and D. P. Rall, Veterans at Risk: The Health Effects of Mustard Gas and Lewisite, National Academy Press (US), Washington (DC), 1993; (b) Spiez Laboratory, Factsheet: Senfgas, https://www.labor-spiez.ch/pdf/de/dok/ fas/FS-Senfgas_d.pdf, accessed 12.09.2017; (c) The National Institute for Occupational Safety and Health. $C D C$ - The Emergency Safety and Health Database: Blister Agent: SULFUR MUSTARD, https://www.cdc.gov/niosh/ershdb/ emergencyresponsecard_29750008.html, accessed 04.06.2017; (d) M. P. Shkarjian, D. E. Heck, J. P. Gray, P. J. Sinko, M. K. Gordon, R. P. Casillas, N. D. Heindel, E. R. Gerecke, D. L. Laskin and J. D. Laskin, Toxicol. Sci., 2010, 114, 5-19.

5 (a) M. Balali-Mood, R. Mathews, R. Pita, P. Rice, J. Romano, H. Thiermann and J. L. Willems, Practical Guide for Medical Management of Chemical Warfare Casualties, OPCW, 2016; (b) U. S. Department of Health and Human Services, Agency for Toxic Substances and Disease Registry, Toxicological
Profile for Sulfur Mustard (update), 2003; (c) M. Balali-Mood and M. Abdollahi, Basic and Clinical Toxicology of Mustard Compounds, Springer International Publishing Switzerland, 2015.

6 F. Gandor, M. Gawlik, H. Thiermann and H. John, J. Anal. Toxicol., 2015, 39, 270-279.

7 D. Noort, D. H. J. M. Platenburg and H. P. Benshop, Bioorg. Med. Chem. Lett., 1996, 6, 2007-2012.

8 (a) A. Fidder, G. W. H. Moes, A. G. Scheffer, G. P. van der Schans, R. A. Baan, L. P. A. de Jong and H. P. Benshop, Chem. Res. Toxicol., 1994, 7, 199-204; (b) M. Batal, I. Boudry, S. Mouret, C. Cléry-Barraud, J. Wartelle, I. Bérard and T. Douki, Toxicol. Appl. Pharmacol., 2014, 278, 39-44.

9 M. Batal, S. Rebelo-Moreira, N. Hamon, P.-A. Bayle, S. Mouret, C. Clériy-Barraud, I. Boudry and T. Douki, Toxicol. Lett., 2015, 233, 1-7.

10 (a) R. M. Black, J. M. Harrison and R. W. Read, Xenobiotica, 1997, 27, 11-32; (b) R. M. Black, J. Anal. Toxicol., 2008, 32, 29; (c) R. M. Black, R. J. Clarke, J. M. Harrison and R. W. Read, Xenobiotica, 1997, 27, 499-512; (d) D. Noort, A. G. Hulst, L. P. A. de Jong and H. P. Benshop, Chem. Res. Toxicol., 1999, 12, 715-721; (e) D. Noort, A. Fidder, A. G. Hulst, L. P. A. de Jong and H. P. J. Benshop, J. Appl. Toxicol., 2000, 20, S187-S192.

11 (a) F. Aslund, K. D. Bernd and A. Holmgren, J. Biol. Chem., 1997, 272, 30780-30786; (b) H. Sies, Free Radical Biol. Med., 1999, 27, 916-921; (c) M. Hirata, Drug Metab. Pharmacokinet., 1992, 7, 113-131; (d) B. Ketterer, B. Coles and D. Meyer, Environ. Health Perspect., 1983, 49, 59-69.

12 R. M. Black, K. Brewster, R. J. Clarke, J. L. Hambrook, J. M. Harrison and D. J. Howells, Xenobiotica, 1992, 22(4), 405-418.

13 M. Siegert, A. Kranawetvogl, H. Thiermann and H. John, Toxicol. Lett., 2018, 293, 31-37.

14 M. Halme, M. Pesonen, U. Hakala, M. Pasanen, K. Vähäkangas and P. Vanninen, Rapid Commun. Mass Spectrom., 2015, 29, 1279-1287.

15 D. Noort, E. H. Jacobs, A. Fidder, L. P. A. de Jong, J. W. Drijfhout and H. P. Benshop, Int. J. Pept. Protein Res., 1995, 45, 497-500.

16 B. Li, M. Berliner, R. Buzon, C. K. F. Chiu, S. T. Colgan, T. Kaneko, N. Keene, W. Kissel, T. Le, K. R. Leeman, B. Marquez, R. Morris, L. Newell, S. Wunderwald, M. Witt, J. Weaver and Z. Zhang, J. Org. Chem., 2006, 71, 9045-9050.

17 Y.-S. Liu, C. Zhao, D. E. Berbreiter and D. Romo, J. Org. Chem., 1998, 63, 3471-3473.

18 S. Nowshuddin, M. N. A. Rao and A. R. Reddy, Synth. Commun., 2009, 39, 2022-2031.

19 V. Gatterdam, T. Stoess, C. Menge, A. Heckel and R. Tampé, Angew. Chem., Int. Ed., 2012, 51, 1-5. 